\title{
Trailing Vortex-Induced Loads During Close Encounters in Cruise
}

\author{
Michael R Mendenhall ${ }^{1}$ and Daniel J Lesieutre ${ }^{2}$ \\ Nielsen Engineering \& Research, Inc., Santa Clara, CA 95050 \\ Michael J Kelly ${ }^{3}$ \\ NASA Engineering and Safety Center, Hampton, VA 23681
}

\begin{abstract}
The trailing vortex induced aerodynamic loads on a Falcon $20 \mathrm{G}$ business jet flying in the wake of a DC-8 are predicted to provide a preflight estimate of safe trail distances during flight test measurements in the wake. Static and dynamic loads on the airframe flying in the near wake are shown at a matrix of locations, and the dynamic motion of the Falcon 20G during traverses of the DC-8 primary trailing vortex is simulated. Safe trailing distances for the test flights are determined, and optimum vortex traverse schemes are identified to moderate the motion of the trailing aircraft during close encounters with the vortex wake.
\end{abstract}

\section{Nomenclature}

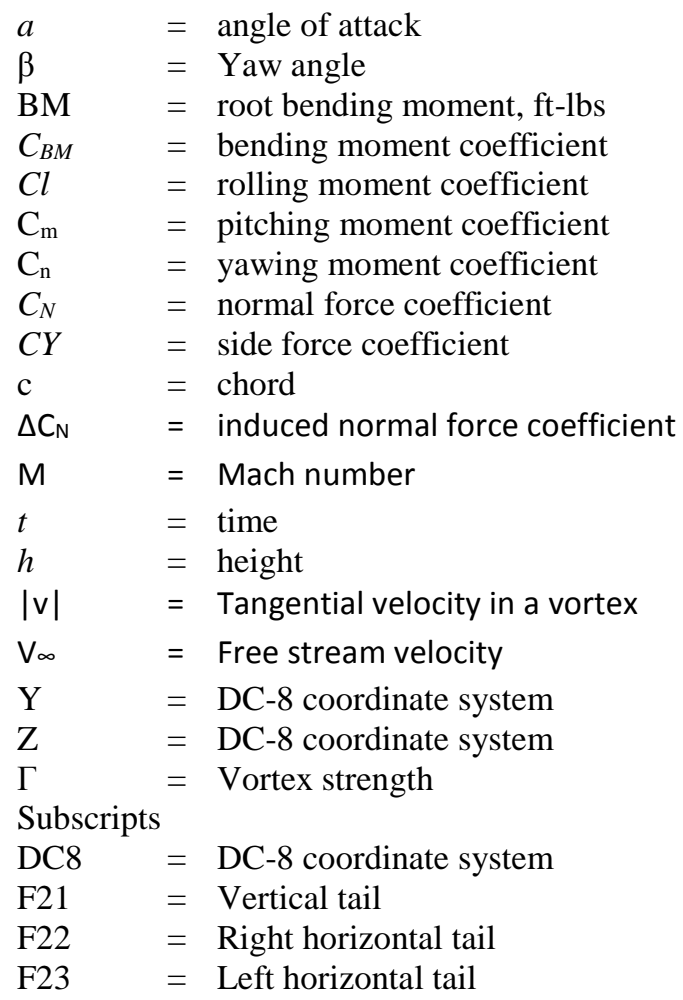

\footnotetext{
${ }^{1}$ President, 900 Lafayette St. Suite 600, Associate Fellow.

${ }^{2}$ Senior Research Engineer, 900 Lafayette St. Suite 600, Senior Member.

${ }^{3}$ Associate Principal Engineer, Langley Research Center M/S 115.
} 


\section{Introduction}

$\mathrm{T}$

he NASA ARMD Fundamental Aeronautics Program's Subsonic Fixed Wing project conducted experimental flight tests to investigate the potential for alternative fuels to reduce the impact of aviation on air quality and climate. ${ }^{1}$ Two series of flight tests in 2013 and 2014 by the Alternative Fuel Effects on Contrails \& Cruise Emissions (ACCESS) project were accomplished using a NASA DC-8-72 transport jet aircraft (Fig. 1) modified to burn alternative fuel and a NASA Falcon 20G (HU-25C) business jet (Fig. 2) that was specially instrumented to collect engine exhaust emission data.

Prior to the flight tests, it was necessary to conduct an independent analysis of the maximum vortex induced loads on the HU-25C for pre-flight safety analysis and to define safe trail distances for the flight tests. Since there were planned excursions through the DC-8 trailing vortices during ACCESS-II, optimum traverse procedures needed to be investigated to understand the HU-25C dynamic structural loads and to provide the pilots with advance information on the handling of the aircraft during these close encounters.

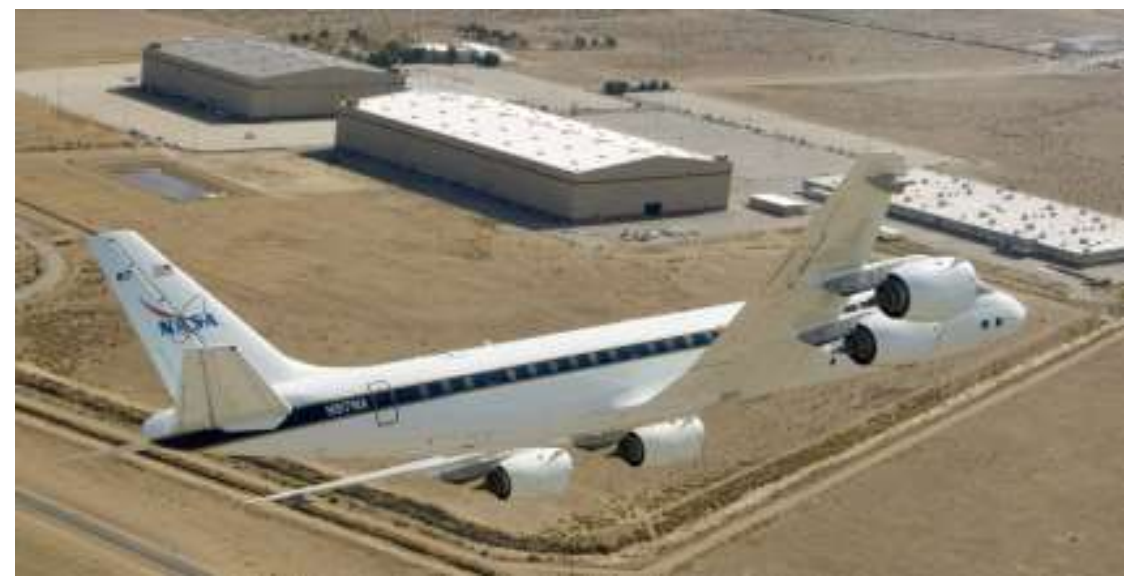

Figure 1.- DC-8-72 Aircraft.

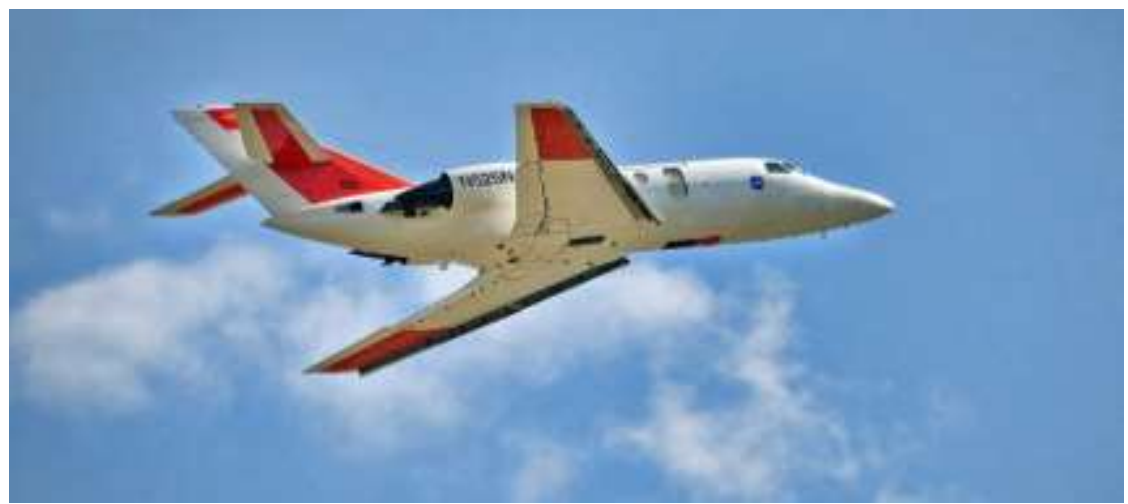

Figure 2.- Falcon 20G (HU-25C) Aircraft.

The objectives of this paper are to describe the methodology used to predict the static and dynamic trailing vortexinduced loads on the HU-25C airframe and to predict the motion of the aircraft in the close proximity of the DC-8 trailing vortex system. Safe trail distances for the flight tests are defined by the maximum induced loads and bending moments on the tail components of the HU-25C. 


\section{Background}

The ACCESS research team was tasked to conduct experimental tests to investigate the potential for alternative fuels to reduce the impact of aviation on air quality and climate. A series of flight tests in 2013 and 2014 were planned using a NASA DC-8-72 transport jet aircraft, modified to burn biofuel in some engines, and a NASA Falcon 20G (HU-25C) business jet aircraft, instrumented to collect engine exhaust emission data. The HU-25C was to collect data behind the DC-8 at cruise altitudes within two experimental zones referred to as the "near field" and the "far field." Near-field distances were usually measured as multiples of leader aircraft wingspan lengths behind the leader aircraft. Far-field distances were usually measured in nautical miles behind the leader aircraft. In the initial flight tests for ACCESS-I in 2013 the Falcon pilot deliberately avoided direct contact with the DC-8 wake vortices, but for ACCESS-II in 2014 the HU-25C pilot deliberately traversed the wake vortices.

One safety hazard identified with flying in close proximity to the DC- 8 trailing wake vortices was structural failure of components of the airframe. The ACCESS team made estimates of the trailing vortex-induced aerodynamic loads on the HU-25C using a simplified aerodynamic model, and a safe operating flight envelope was developed based on maintaining maximum induced loads less than $70 \%$ of the design limit loads for the critical components of the aircraft.

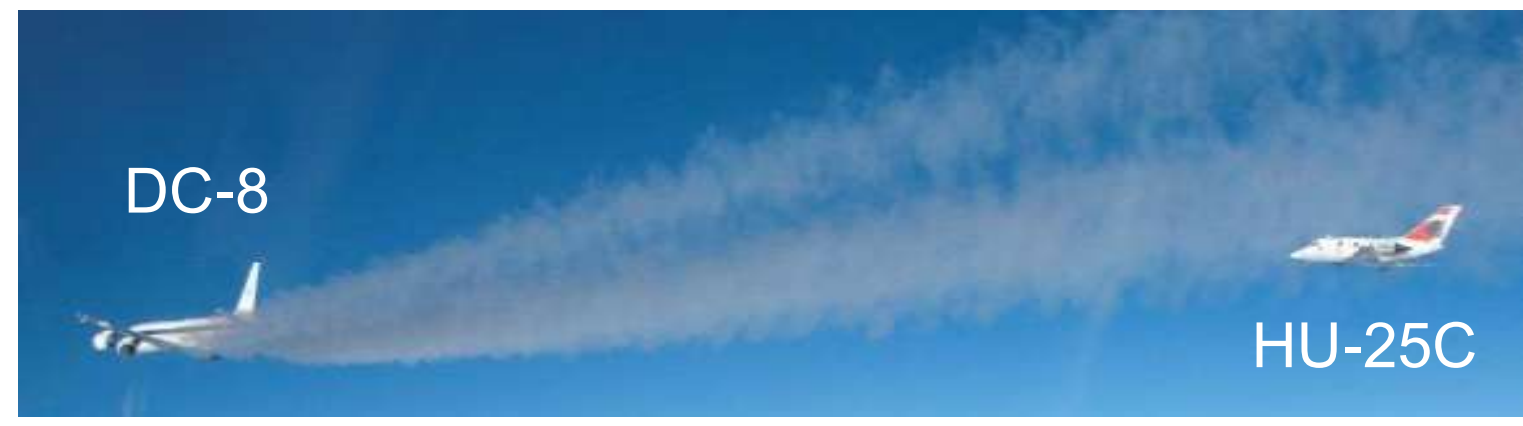

Figure 3. ACCESS Flight Test.

By request of the ACCESS Project, ${ }^{2}$ the NASA Engineering Safety Center (NESC) formed a team to provide an independent assessment of the safe trail distance of the HU-25C aircraft in the wake of the DC-8 and in close proximity with the trailing vortices. The approach for this independent assessment involved the following:

- Determine the wake flow conditions for the area to be probed.

- Compare certification loads for the probing aircraft to the predicted maximum induced loading from DC-8 trailing vortices and determine a safe operating envelope.

- Evaluate crew safety/egress during wake vortex traverses.

These specific topics are the focus of the work reported in this paper. It should be noted that time and resources available to the NESC team and the large number of flight conditions to be examined did not permit the use of wind tunnel testing or computational fluid dynamics. Instead, the team used proven aerodynamic prediction tools which were readily available for application to this problem. These tools and the flow models are described in the following sections.

\section{Technical Approach}

\section{A. Aircraft Models}

Sufficient geometry data are available to create analysis models for both the DC-8 and HU-25C aircraft with panels. Both aircraft were modeled in cruise, and both aircraft were trimmed under free-stream flight conditions by iterating on angle of attack and horizontal tail deflection until zero pitching moment was achieved at lift equal to weight. Thrust was presumed to be equal to drag under trimmed conditions, and the center-of-gravity location was assumed to be at the quarter-chord of the mean aerodynamic chord. The nominal trim angle of attack of the DC-8 was approximately $1.35^{\circ}$, and the trim angle of attack of the $\mathrm{HU}-25 \mathrm{C}$ was approximately $1.0^{\circ}$ based on these assumptions. When the HU-25C needed to be trimmed in roll under the influence of the DC-8 wake, a constant roll moment was added to the wings to counter the wake-induced rolling moment. Note that the trim conditions changed for each weight, speed, and altitude considered for the flight tests. 


\section{B. Trailing Vortex Models}

The trailing vortex wake associated with the DC-8 must be modeled such that a realistic induced velocity field can be produced to interact with the HU-25C at various locations aft of the DC-8. Traditional and proven vortex modeling techniques were selected to predict the vortex-induced velocities acting on the HU-25C at any position relative to the DC-8 wake.

The wake aft of the DC-8 is a product of the aircraft model, and immediately aft of the airplane, the wake can be represented as a distribution of discrete vortices originating along the span of the wing and horizontal tail. The flow models used for the wake interference can handle this distribution of vortices; however, these vortices tend to roll up very quickly into a primary trailing vortex from the wing and one from the tail. The DC- 8 wake model used for the interference calculations described below is a simplified model made up of a wing primary trailing vortex and several other vortices originating from the inner wing segment and the horizontal tail. Note that the trailing vortices are not allowed to move in space, and the HU-25C is located relative to the fixed vortex locations. In the current model, the HU-25C does not influence the position of the DC- 8 vortices, but the vortices are not allowed to penetrate the $\mathrm{HU}-25 \mathrm{C}$ airframe.

The theoretical tangential velocity induced by a potential trailing vortex has a singularity at the center of the vortex, and there are several historical core models available to represent the viscous core of the vortex. The core diameter is usually defined as a percent of the wing span of the generating aircraft, and for this analysis the core diameter was varied from $1 \%$ to $3 \%$ of the DC-8 span. The core radius impacts the maximum induced loads on the HU-25C, but only over a small spatial region around the trailing vortex.

There are different models for the velocity profile through the vortex core, and the choice of this model can have an impact on the level of conservatism in the results. Two common models for the velocity profile through the vortex core are the Lamb-Oseen model and the Burnham-Hallock model. The details of these models are described in Refs. 3-5, and examples of the two velocity profiles are shown in Fig. 4 for a core radius equal to 1\% of the DC-8 wing span. The Burnham-Hallock model with a core diameter of $1.5 \%$ of the DC-8 wing span was used for most of the results to follow.
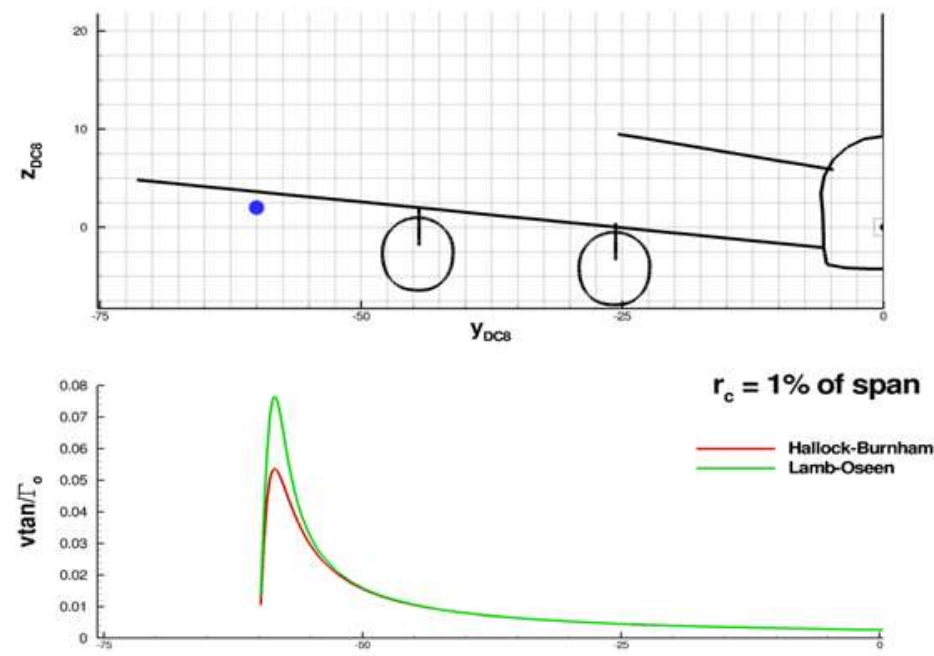

Figure 4. Velocity Profiles Through a Trailing Vortex.

In addition to the vortex core model, it has been observed that the strength of the trailing vortex decays with distance aft of the generating aircraft. A three-phase model of vortex strength decay as a function of distance behind the DC-8 (weak decay in the near field, followed by rapid decay as the vortices rolled up, followed by gradual decay in the mid and far field) was based on the results described in Refs. 3-5.

\section{Aerodynamic Prediction Methods}

The NESC team performed aerodynamic loads and flight dynamics studies using Nielsen Engineering and Research (NEAR) aerodynamic prediction codes: the STRLNCH store separation analysis tools (Refs. 6-9) and the Missile Distributed Loads (MISDL) codes (Refs. 10-16). These were developed by NEAR and have been validated 
with flight data for numerous applications. They have the advantage of being fast running and suitable for the large number of simulations required for this independent assessment.

The MISDL code was used to model the DC-8 and HU-25C aircraft. The DC- 8 was modeled to determine its trailing vortex wake at trimmed flight conditions. The HU-25C was modeled to predict the aerodynamic loads acting on it in the free stream and when immersed in the trailing wake of the DC- 8 aircraft. MISDL is a singularity and panel-method-based aerodynamic prediction method, which includes high-angle-of-attack body and lifting surface vortex models, rotational rates, and nonuniform flow effects. MISDL is capable of modeling noncircular bodies and surfaces with arbitrary planforms, orientations, and dihedral angles. Rotational rates and nonuniform flow effects are included in the modeling so that flight dynamic analyses can be performed. MISDL uses classical aerodynamic flow models based on solving potential flow equations, Laplace's equation with compressibility corrections, classical singularity methods augmented with body and fin vortex modeling, and wing stall models based on empirical data.

Predicted span-load distributions for a DC-8 wing and horizontal tail are shown in Fig. 5 below for an assumed nominal DC-8 weight in cruise at Mach 0.66 at an altitude of 30,480 ft. Notice that the fuselage influence and the break in wing trailing-edge sweep cause the span loading to be slightly different from an elliptic loading distribution. DC-8 wake vortices from the MISDL model are shown in Fig. 6.

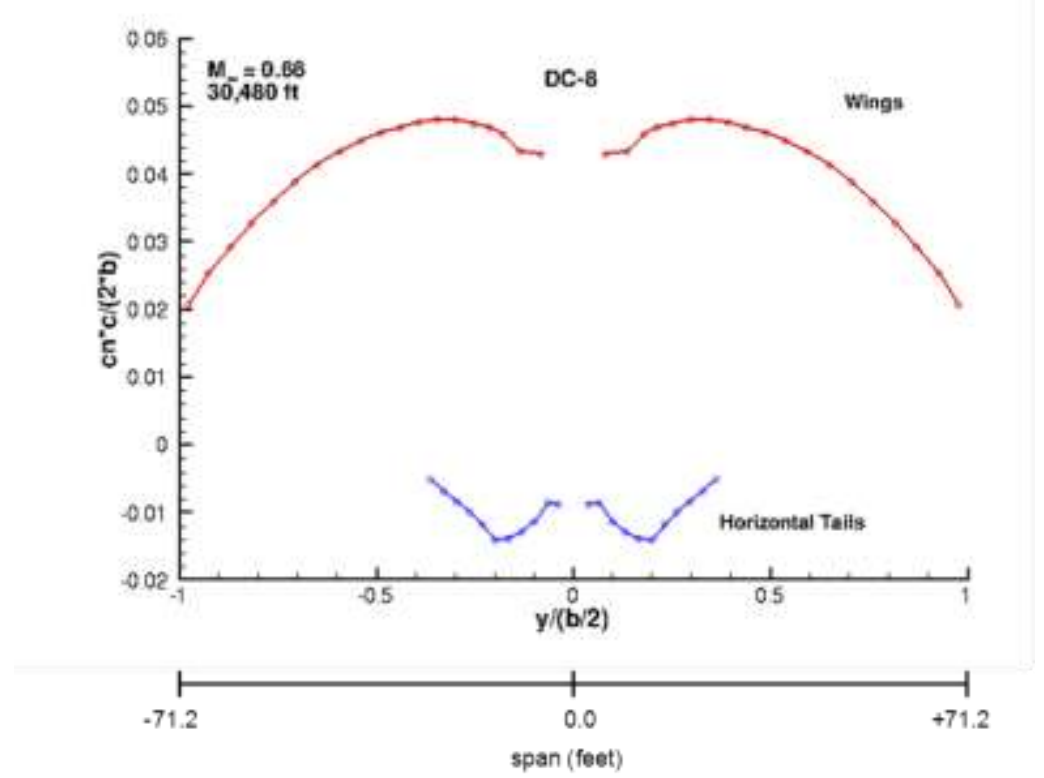

Figure 5. Predicted Span-Load Distributions for DC-8 Wing and Horizontal Tail.

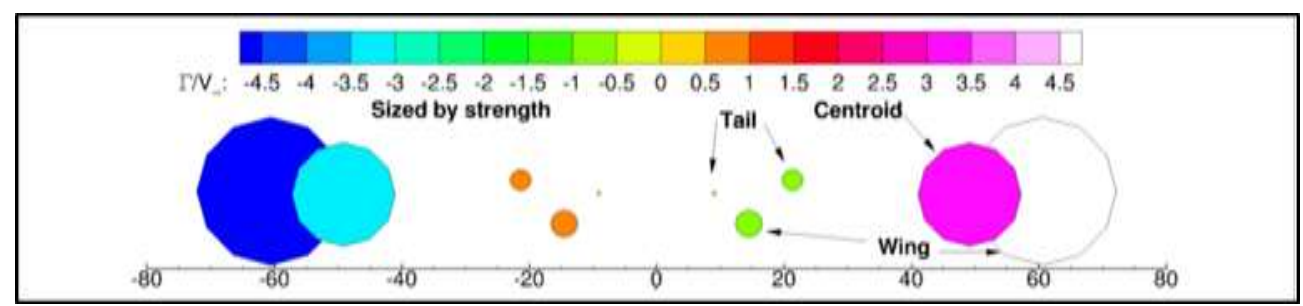

Figure 6. DC-8 Model Wake Vortices.

Shown on each side for a full DC-8 wingspan is one primary wingtip vortex, one secondary vortex associated with an inner wing feature, and two horizontal tail vortices. Engines and pylons were not modeled for this analysis. The size of each symbol represents the relative strength of each vortex. The color represents strength and rotational direction; positive is counterclockwise when viewed looking forward. It can be seen that on a given side of the aircraft, the horizontal tail vortices are opposite in direction to the wing vortices because the wings are generating positive lift and the horizontal tails are generating aerodynamic down forces to balance the aircraft in pitch. Two 
"centroid" vortices are also shown. These are the vortex-strength * position weighted averages of all of the vortices on each side of the aircraft.

The DC-8 trailing wake induced velocity field for a nominal flight condition is shown in Fig. 7. Vectors represent velocity components in the Y-Z plane at the DC-8 tail location. Colors represent these vector component values relative to the free-stream velocity. No decay of the vortex strength has been included for this example.

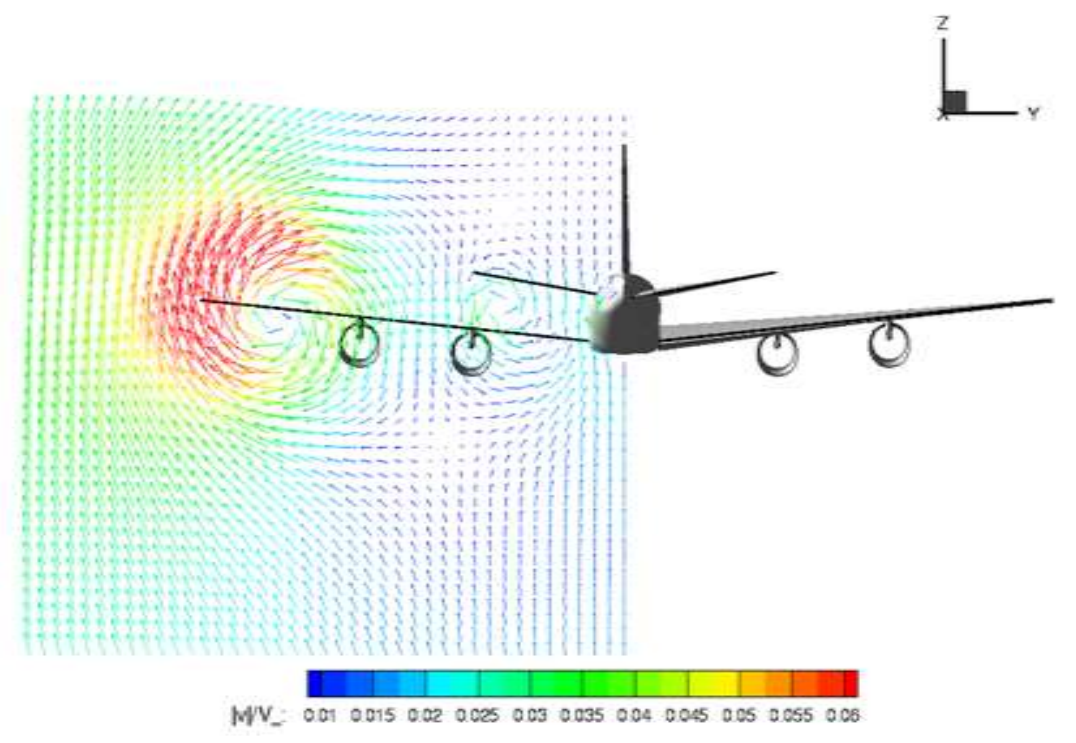

Figure 7. Velocity Flow Field Behind the Model DC-8.

\section{Trajectory Simulations}

The NEAR STRLNCH aircraft store separation simulation code (Refs. 6-9) was used to model and predict 6DOF uncontrolled (stick-fixed) trajectory characteristics of the HU-25C aircraft starting at selected positions directly behind the DC-8. This method had previously been validated with wind-tunnel and flight-test data for many 6-DOF trajectory simulations and flow-field studies for a variety of configurations as documented in Refs. 8, 9, and 17-22.

STRLNCH can model flow effects due to combined angle of pitch and sideslip, as well as rotational rates. The aerodynamic prediction methods described above were used to model $\mathrm{HU}-25 \mathrm{C}$ aerodynamic forces and moments for the simulation. A breakdown of forces and moments on each aircraft component during the simulation is available to determine maximum vortex induced effects.

For each simulation, the HU-25C is trimmed for the selected flight path at the starting point. The HU $25 \mathrm{C}$ is released with no control inputs during the simulation, and each trajectory simulation is run for a fixed time or until the aircraft is out of the influence of the DC- 8 trailing wake.

\section{Results}

\section{A. Static Loads}

The static loads on the HU-25C were predicted at a matrix of locations aft of the DC-8. Overall vortex-induced loads on the aircraft and component loads and bending moments were obtained for a number of flight test conditions and trail distances behind the DC-8. The HU-25C in a cruise trim attitude was placed in the trailing vortex field, and the aerodynamic characteristics in the nonuniform velocity field were calculated. Contour maps were created in a Y$\mathrm{Z}$ plane to illustrate aircraft loads. Example results for the HU-25C aerodynamic characteristics in one flight test condition are shown below for zero trail distance to illustrate the worst case static loads. No vortex decay was used for these near-field results. Computed results for induced rolling moment $(\mathrm{Cl})$, induced normal force $(\Delta \mathrm{CN})$, induced pitching moment $(\mathrm{Cm})$, induced side force $(\mathrm{CY})$, and induced yawing moment $(\mathrm{Cn})$ coefficients acting on the HU-25C are shown in Figs. 8-12.

In the color contour maps shown below, the $\mathrm{HU}-25 \mathrm{C}$ nose placed at a point $(\mathrm{Y}, \mathrm{Z})$ in the DC-8 flow field will produce the aerodynamic characteristic on the aircraft defined by the color bar at the right of each map. Note that the primary DC-8 vortex location $(\mathrm{Y}=-60, \mathrm{Z}=2)$ is shown as a white circle in each figure. For example, in the 
figures below, the HU-25C (Falcon) aircraft is illustrated with the nose located at point $(-50,-50)$. If the nose is moved to the point $(-60,0)$, the rolling moment coefficient on the HU-25C is about 0.28 due to the induced flow from the DC-8 primary trailing vortex, The calculations to generate a set of contour maps for a specific flight condition requires more than 2,000 simulations with the NEAR STRLNCH/MISDL method, and multiple flight conditions and trailing distance were studied over the course of the investigation.

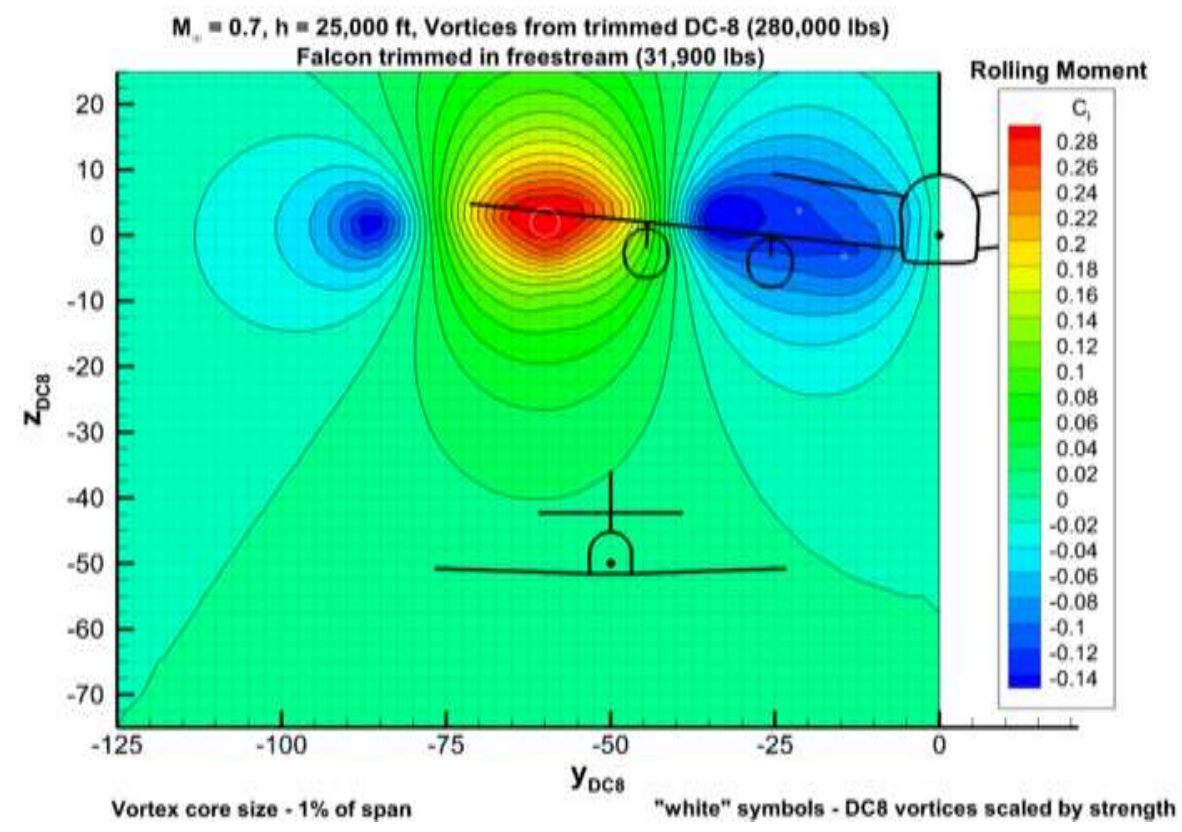

Figure 8. Induced Rolling Moment Coefficient $\left(C_{1}\right)$.

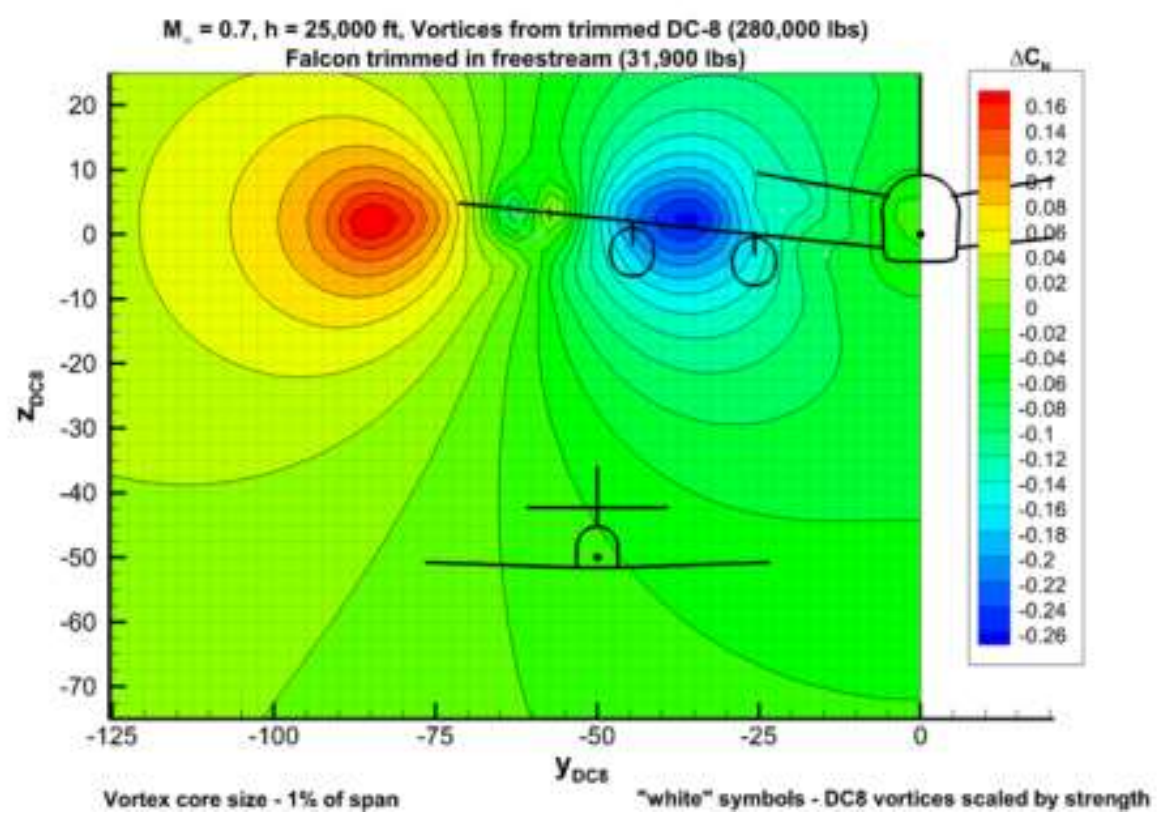

Figure 9. Induced Normal Force Coefficient $\left(\Delta C_{N}\right)$.

American Institute of Aeronautics and Astronautics 


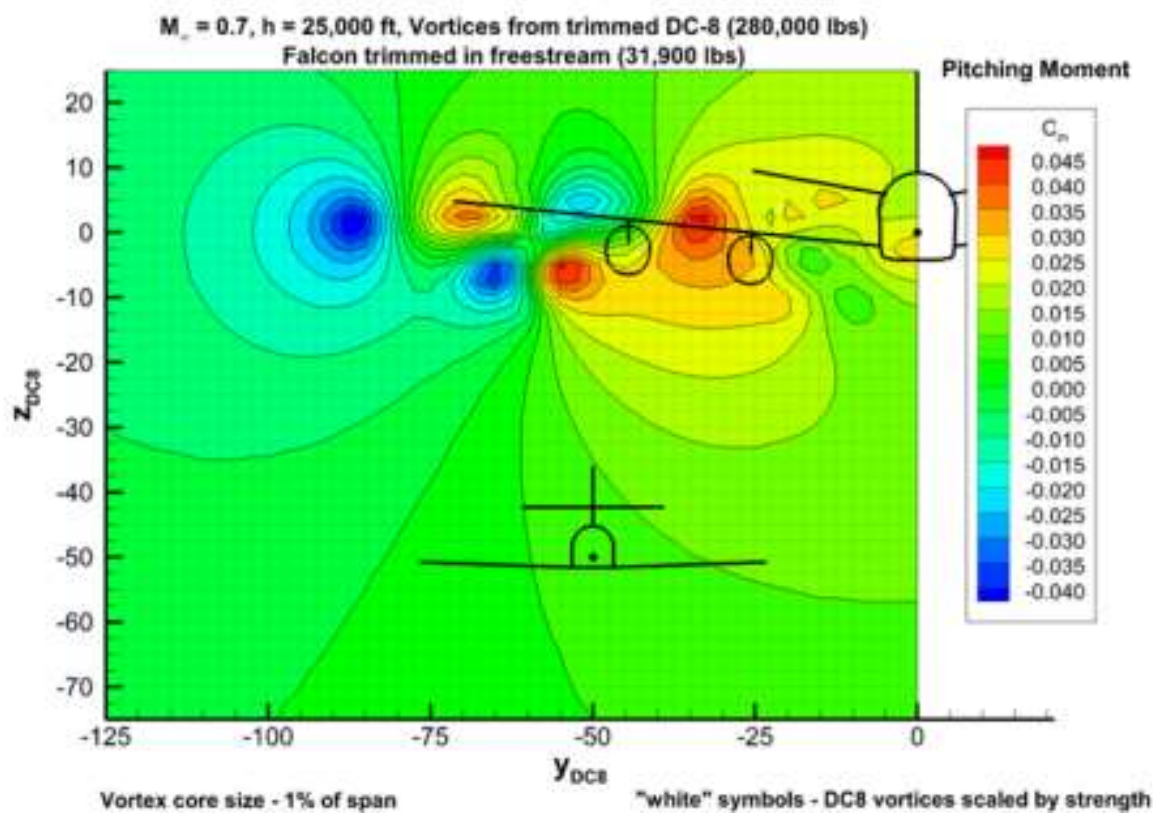

Figure 10. Induced Pitching Moment Coefficient $\left(C_{m}\right)$.

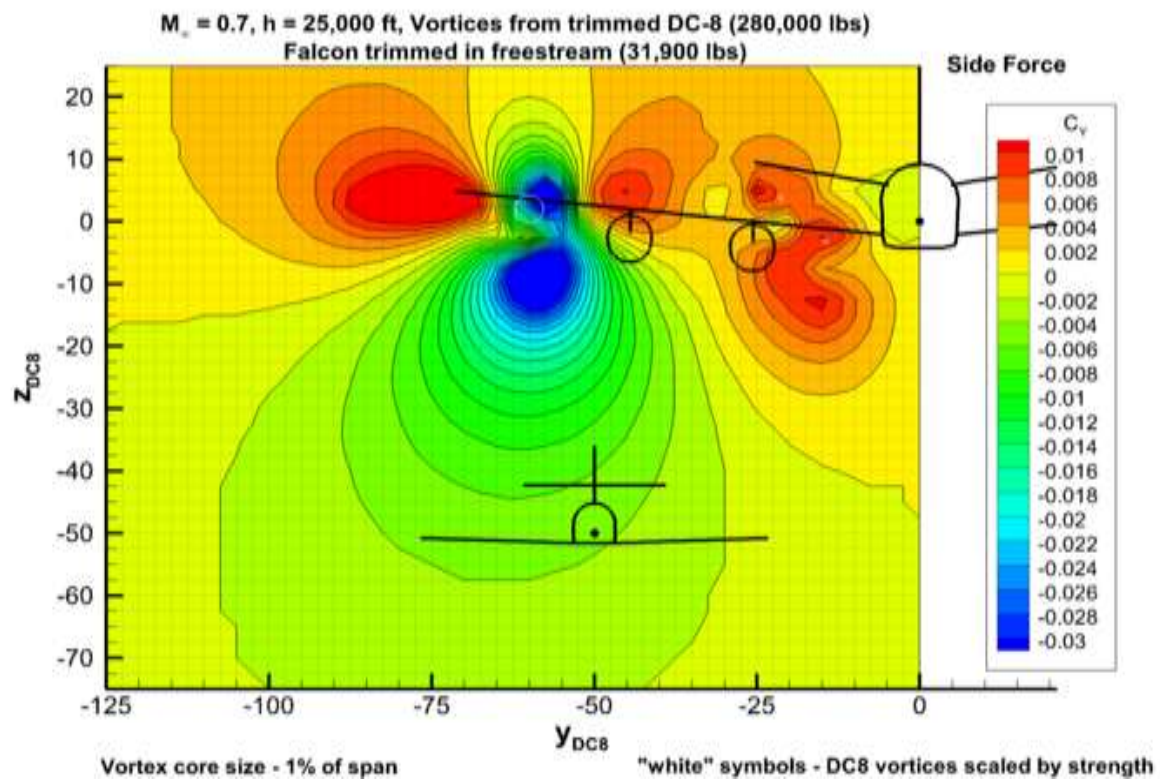

Figure 11. Induced Side Force Coefficient $\left(C_{Y}\right)$.

American Institute of Aeronautics and Astronautics 


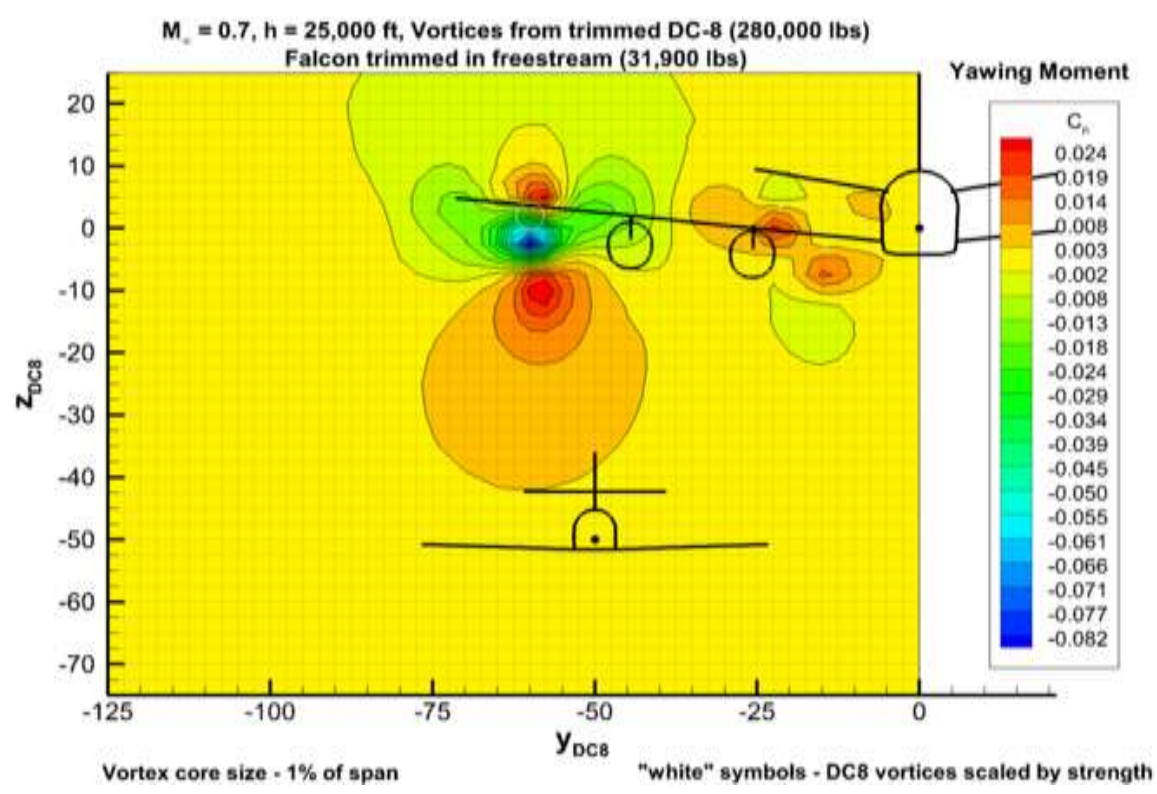

Figure 12. Induced Yawing Moment Coefficient $\left(C_{n}\right)$.

Similar contour maps were generated for the induced normal forces and bending moments on the HU-25C aerodynamic surfaces for the matrix of locations behind the DC- 8 at a range of trail distances. Since the tail components are the most likely to exceed the design limit loads due to vortex interactions, the induced normal force and root bending moment coefficients for the individual tail surfaces are shown below.

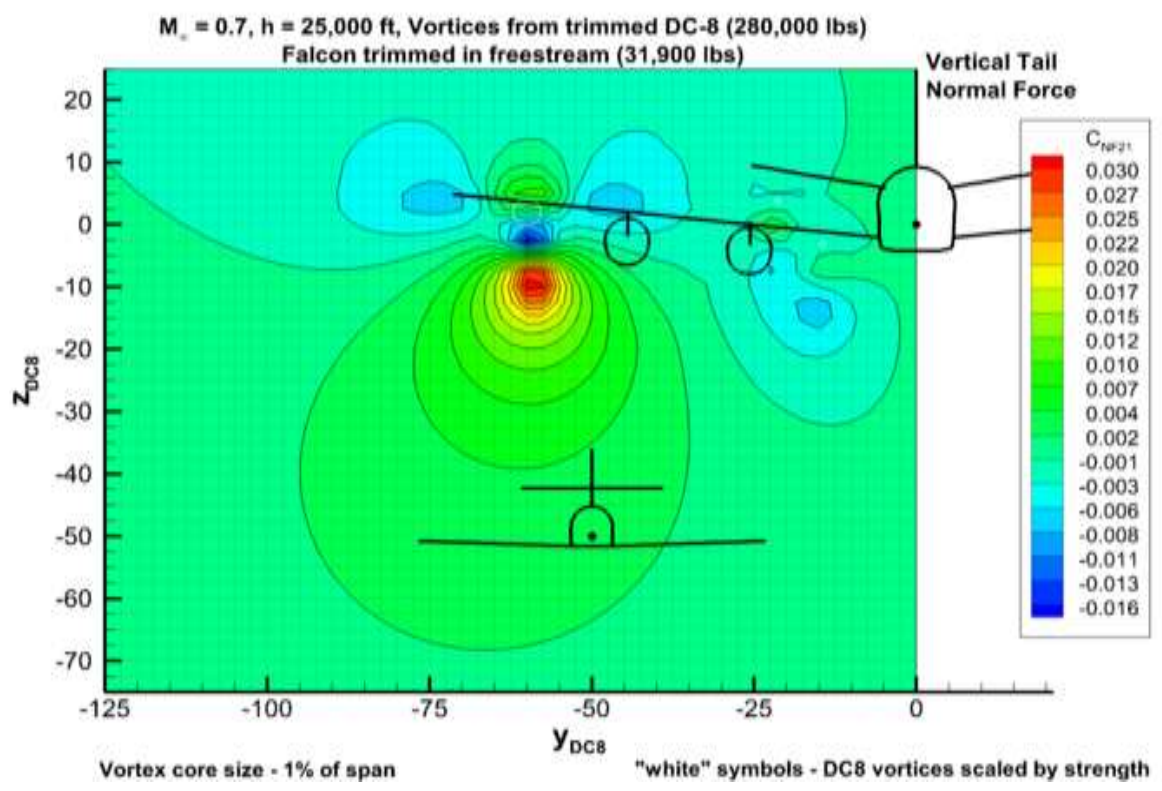

Figure 13. Near-Field Map of HU-25C Vertical Tail Normal Force Coefficient $\left(\mathrm{C}_{\mathrm{NF21}}\right)$. 


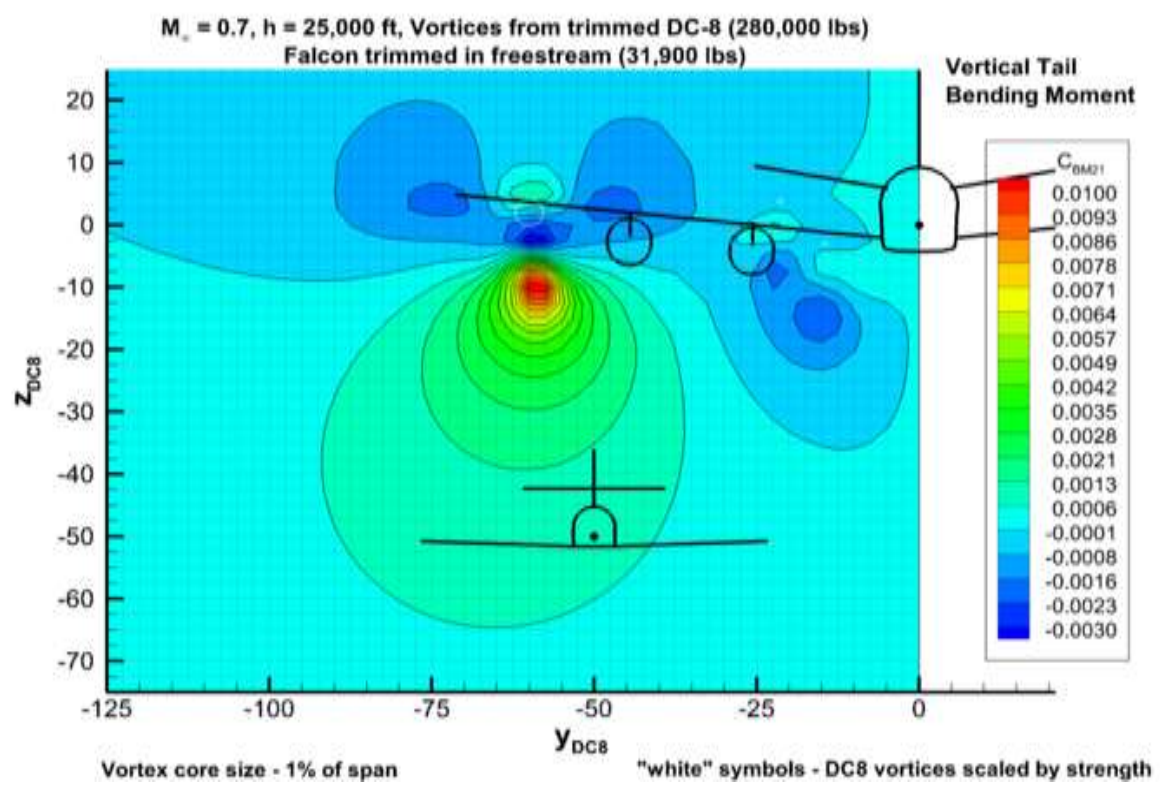

Figure 14. Near-Field Map of HU-25C Vertical Tail Bending Moment Coefficient ( $\left.C_{B M F 21}\right)$.

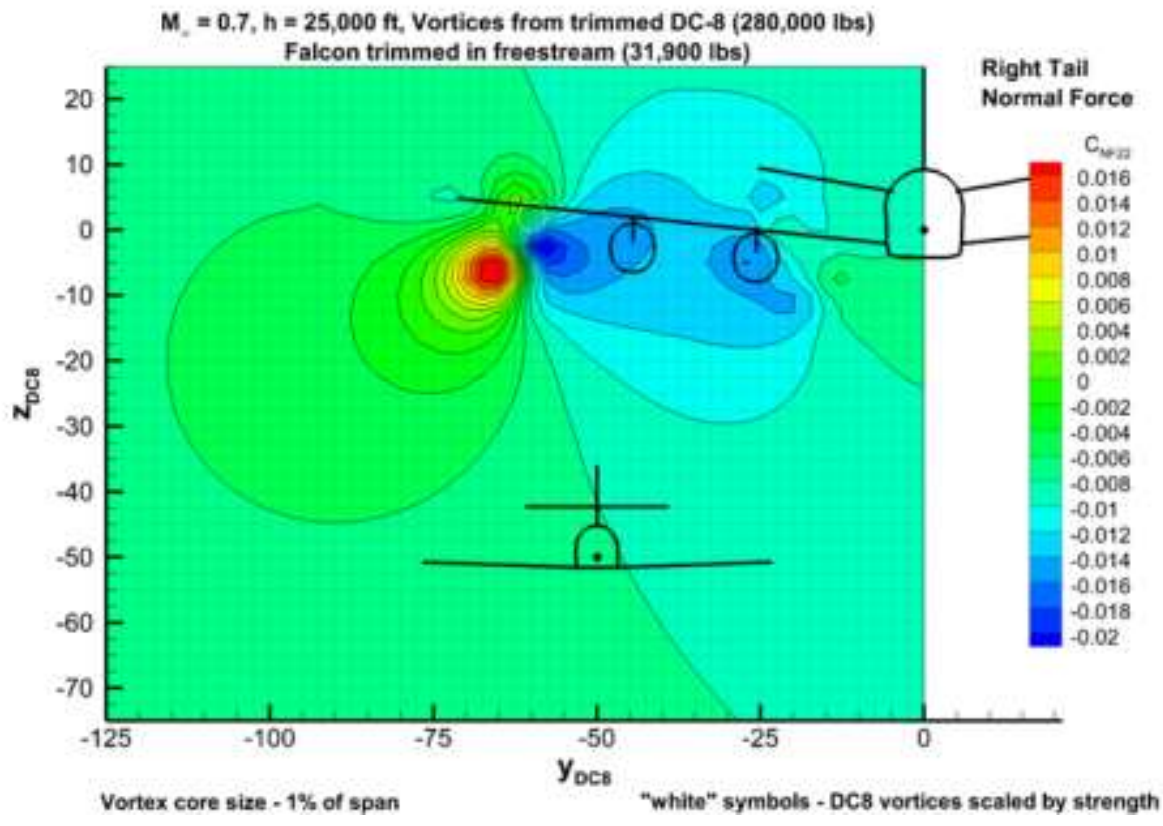

Figure 15. Near-Field Map of HU-25C Right Horizontal Tail Normal Force Coefficient $\left(\mathrm{C}_{\mathrm{NF} 22}\right)$. 


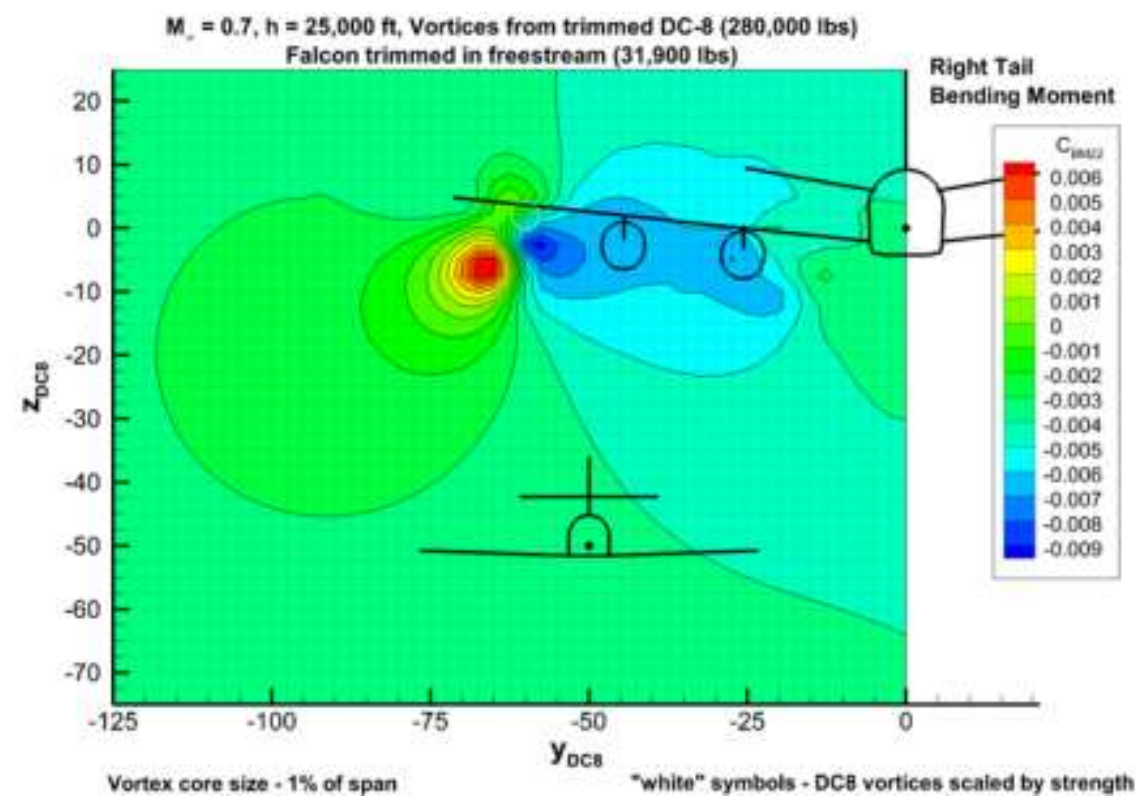

Figure 16. Near-Field Map of HU-25C Right Horizontal Tail Bending Moment Coefficient $\left(\mathrm{C}_{\mathrm{BM2}}\right)$.

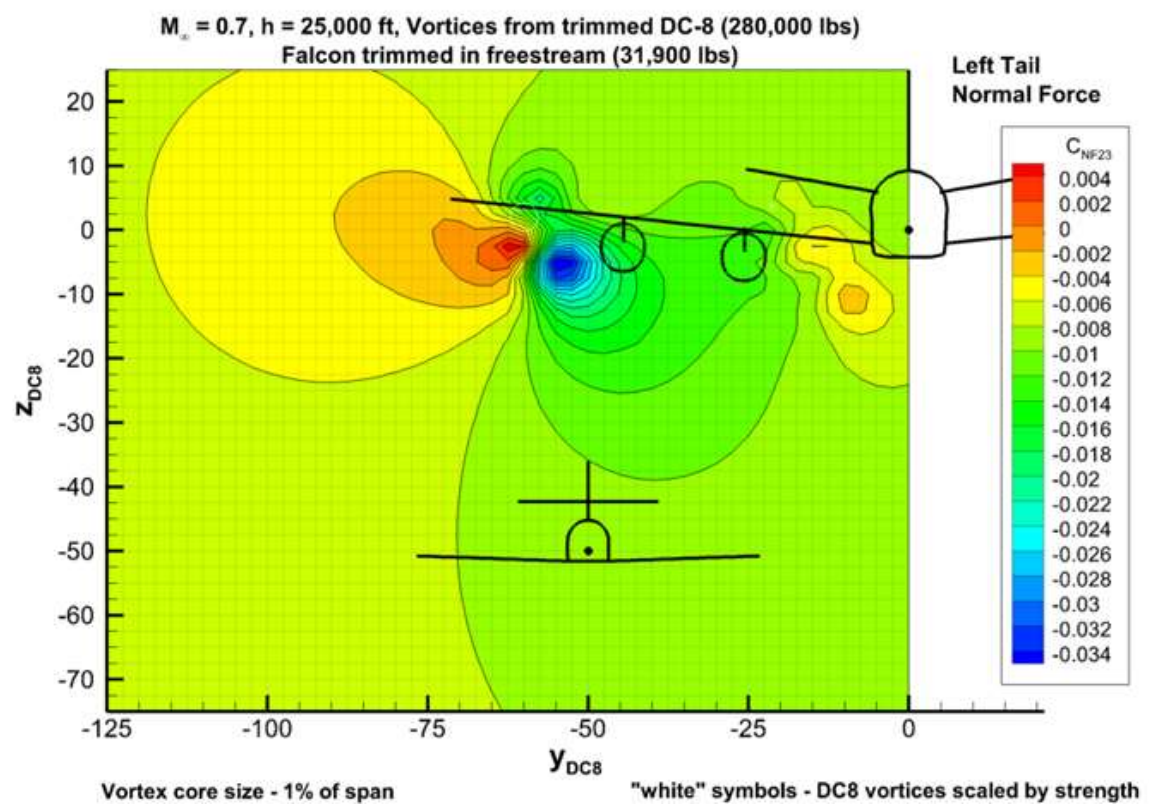

Figure 17. Near-Field Map of HU-25C Left Horizontal Tail Normal Force Coefficient $\left(C_{\mathrm{NF23}}\right)$.

11

American Institute of Aeronautics and Astronautics 


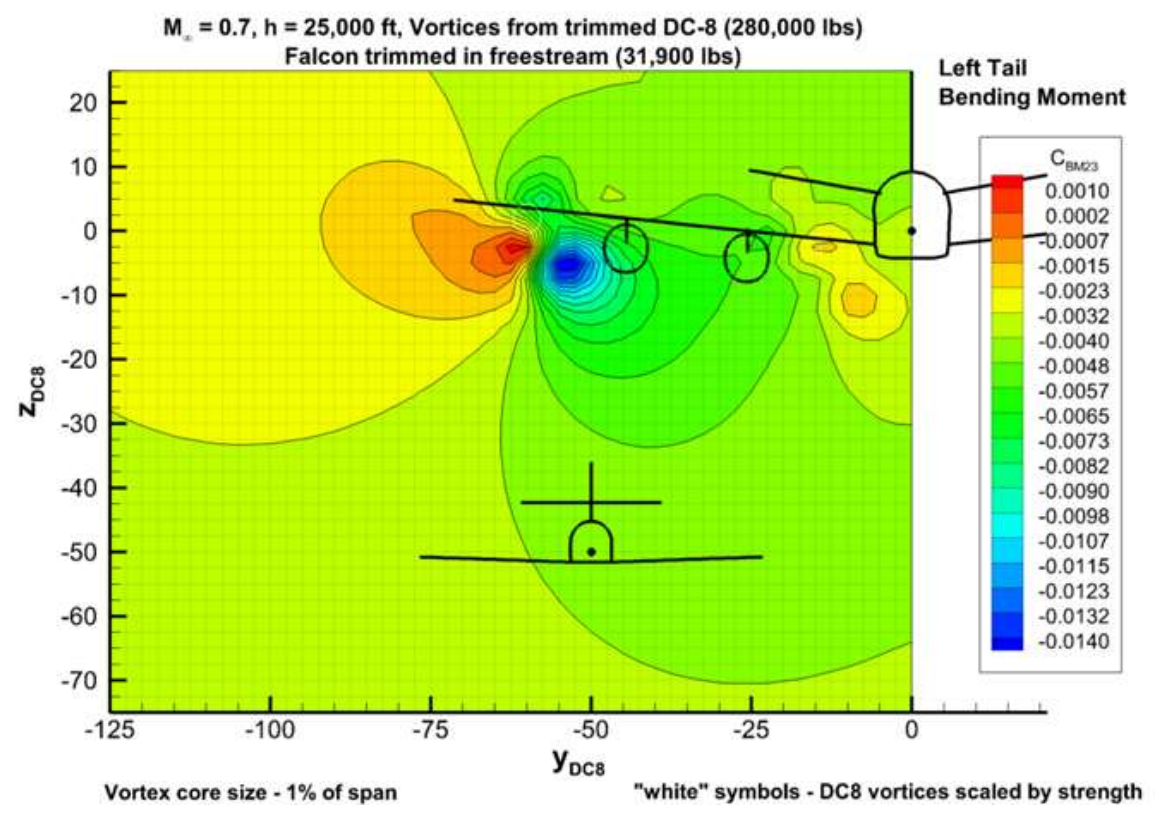

Figure 18. Near-Field Map of HU-25C Left Horizontal Tail Bending Moment Coefficient ( $\left.\mathrm{C}_{\mathrm{BM} 23}\right)$.

\section{B. HU-25 Trajectory Simulations}

Dynamic trajectory simulations of the HU-25C in the DC-8 trailing wake were made to study the changing vortex-induced component loads during traverses of the primary trailing vortex. The purpose of these simulations of both vertical and horizontal traverses was twofold. First, it was important to understand if there was a difference in component vortex-induced loadings for the horizontal and vertical traverses. Second, it was of interest to understand the reaction of the HU-25C to a close encounter with a strong trailing vortex to forewarn the pilots of possible extreme flight conditions.

The flight test plan for a vertical traverse of the DC-8 trailing vortex with the HU-25C was to descend through the vortex from above. The HU-25C was trimmed at an initial position $100 \mathrm{ft}$. above the trailing vortex, such that the aircraft would descend at a 2-degree flight path angle upon release. It would descend stick-fixed into the vortex or wherever the induced flow field dictated it to go. The release point above the vortex was varied from directly above the DC- 8 trailing vortex ( $\mathrm{y}=-60 \mathrm{ft}$.) to approximately $35 \mathrm{ft}$. outboard of the vortex ( $\mathrm{y}=-95 \mathrm{ft}$.). All trajectories were run for seven seconds. The position of the HU-25 is shown every 0.5 seconds to illustrate the trajectory in the following figures. Trail distance of $0 \mathrm{~nm}$ was used for these trajectory simulations because trajectories will be more benign at greater trail distances. 


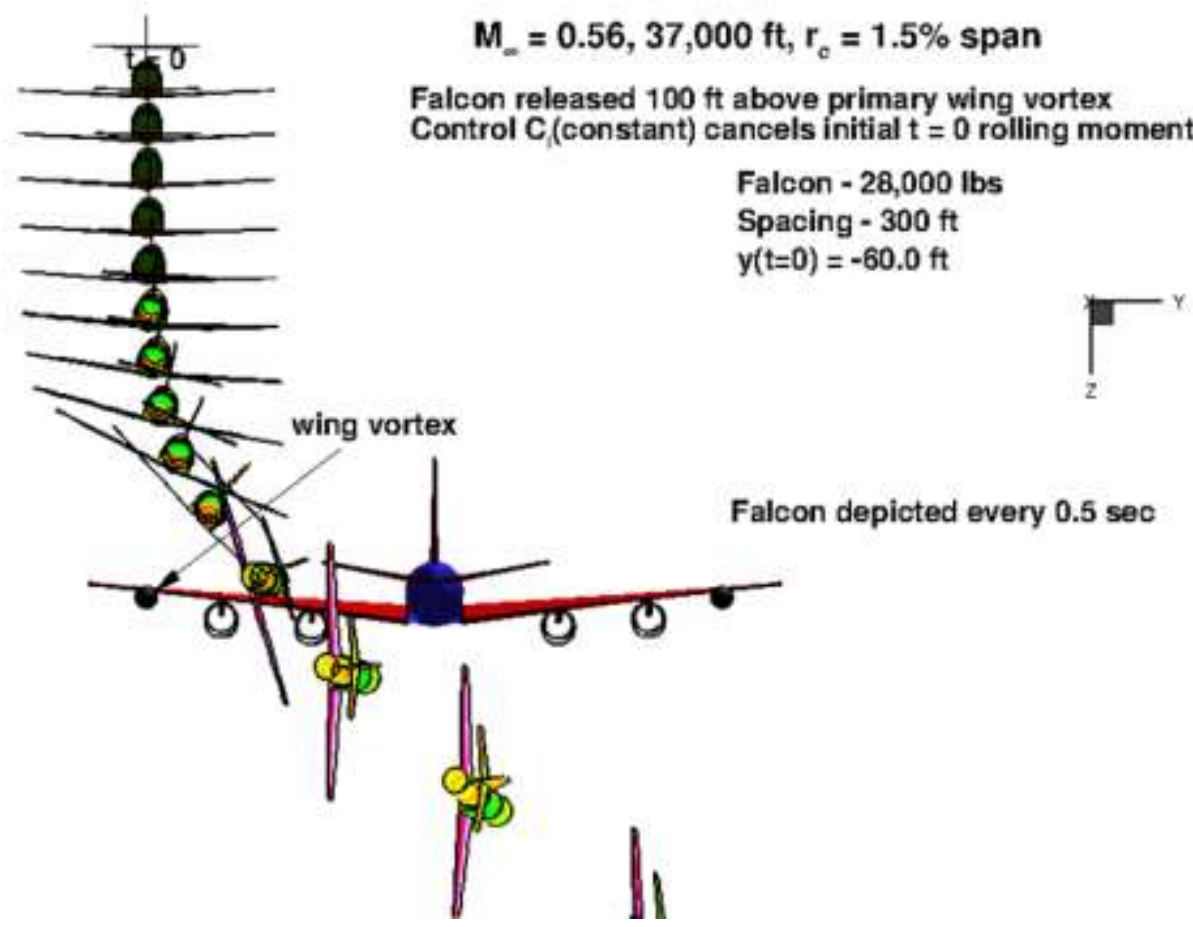

Figure 19. HU-25C Vertical Traverse, $Y(0)=-60 \mathrm{ft}$.

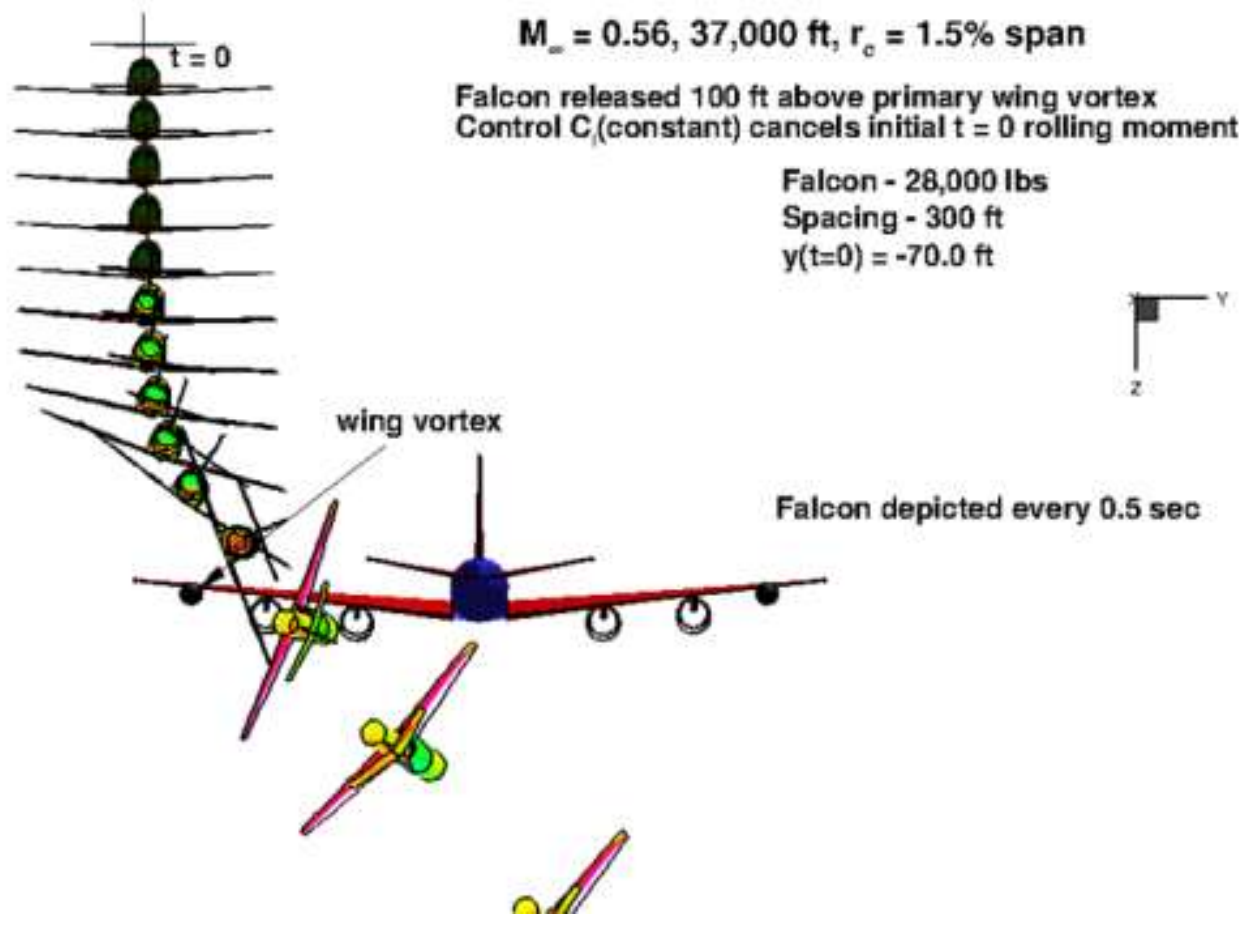

Figure 20. HU-25C Vertical Traverse, $Y(0)=-70 \mathrm{ft}$. 


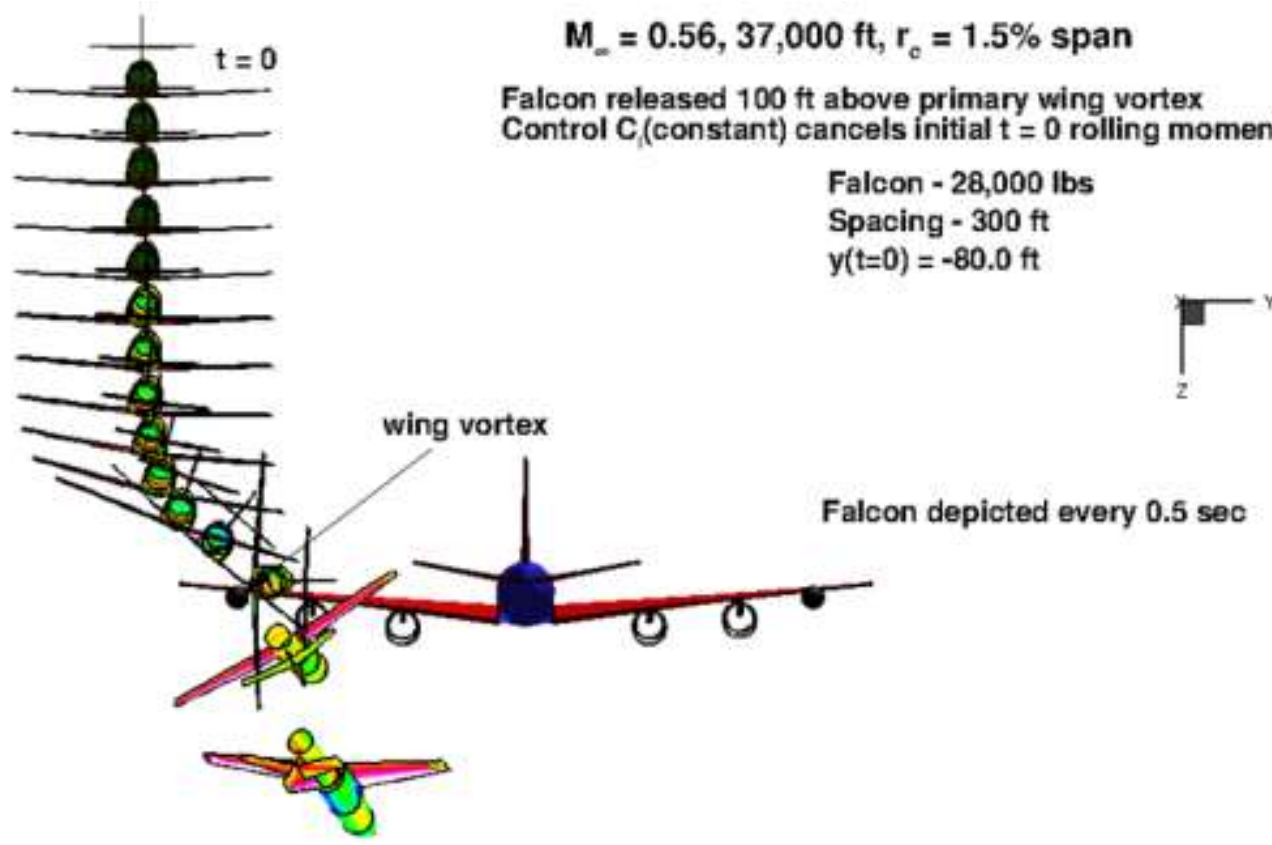

Figure 21. HU-25C Vertical Traverse, $\mathrm{Y}(\mathbf{0})=-\mathbf{8 0} \mathrm{ft}$.

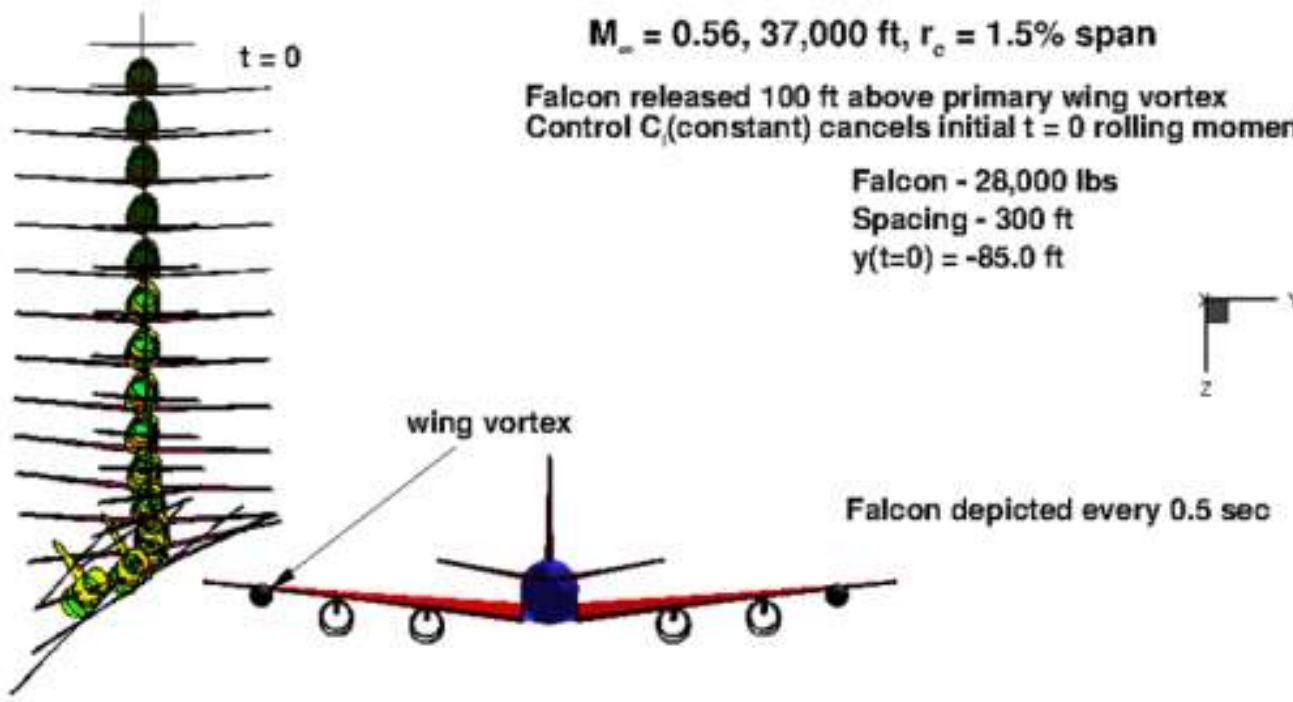

Figure 22. HU-25C Vertical Traverse, $Y(0)=-85 \mathrm{ft}$. 


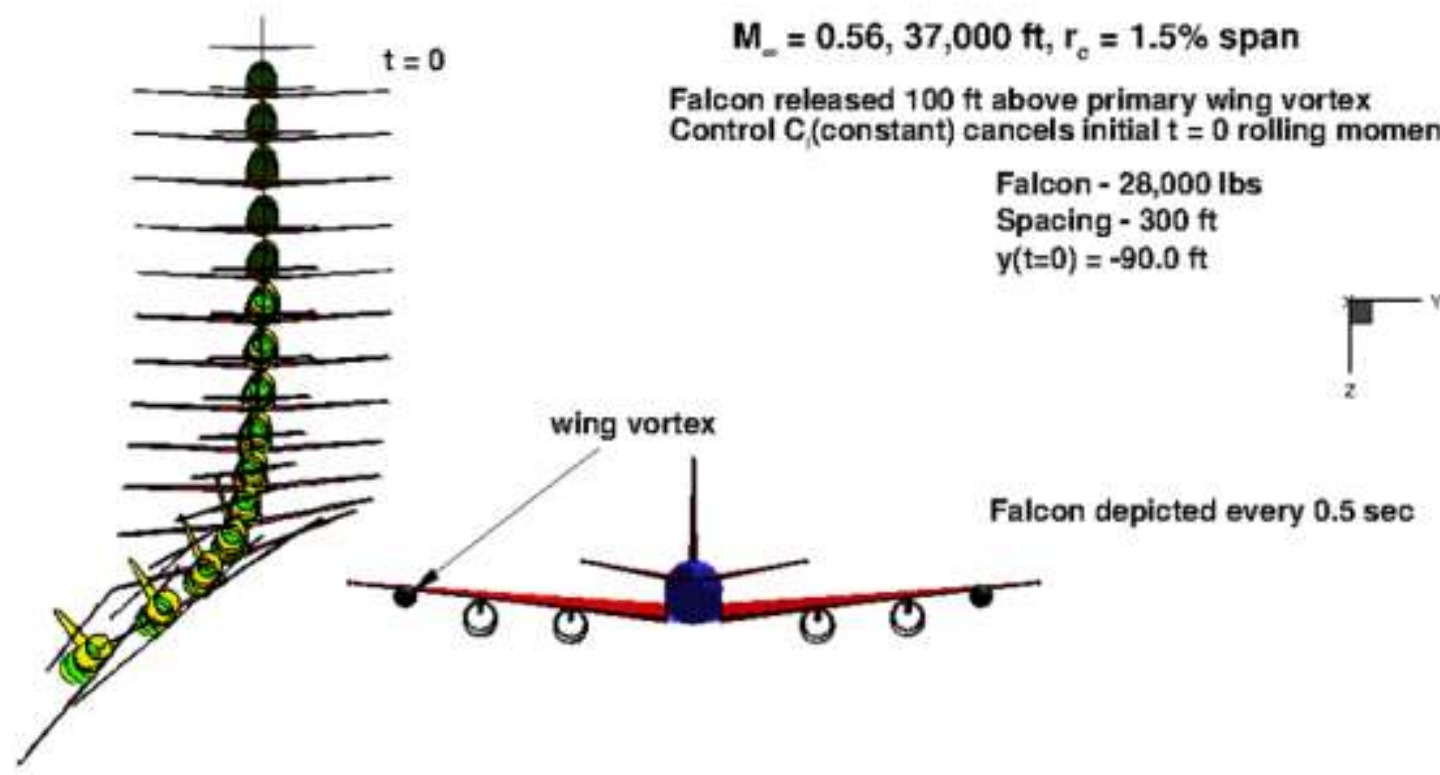

Figure 23. HU-25C Vertical Traverse, $\mathrm{Y}(0)=-90 \mathrm{ft}$.

A similar parametric study of horizontal or lateral flight traverses through the trailing vortex was conducted. The initial study varied the heading angle from 20 degrees to two degrees with the $\mathrm{HU}-25 \mathrm{C}$ at the same height as the primary DC-8 vortex. The influence of the heading angle on the maximum empennage root bending moment is shown in Fig. 24. Notice that at low crossing angles, the bending moment is low, but this is because the primary DC-8 vortex kicked the HU-25C away from the vortex before it had an opportunity to penetrate the vortex. The large crossing angles were determined to not give the HU-25C enough test time in the vicinity of the vortex, so a heading angle of six degrees was selected as a compromise for the lateral traverses.

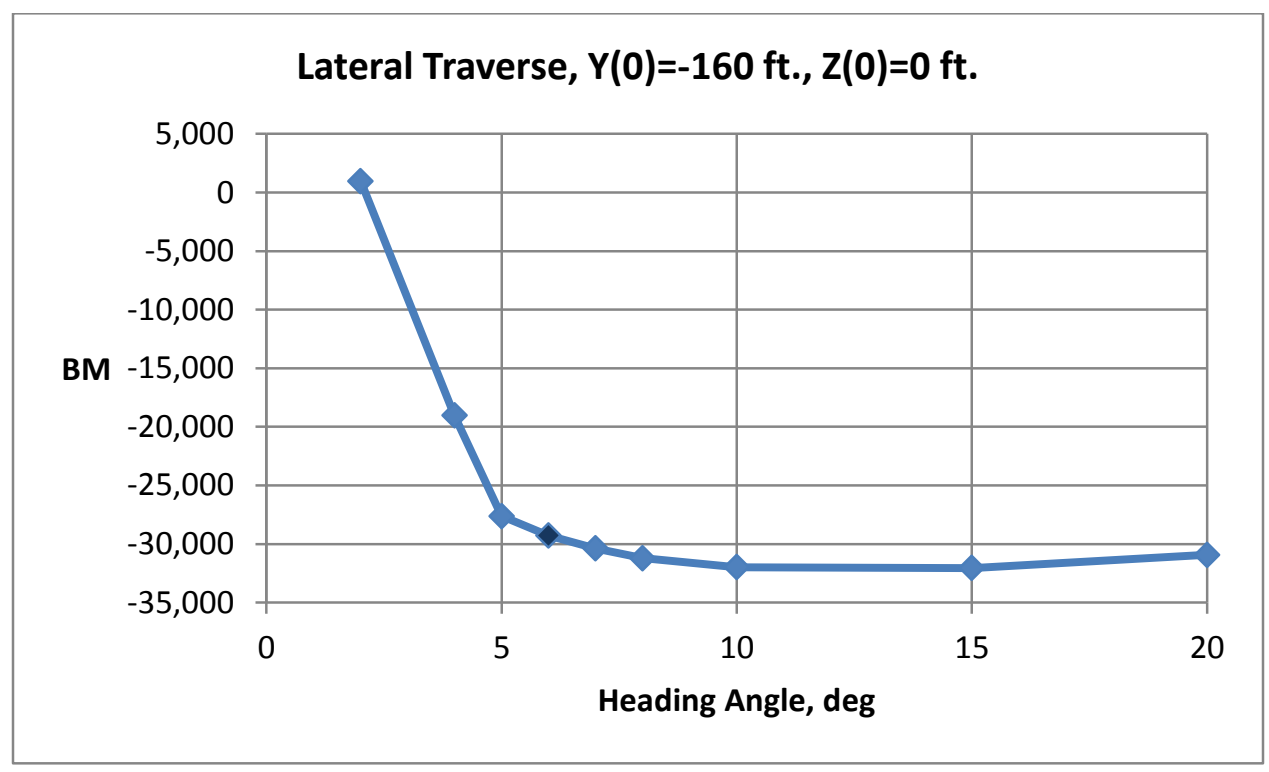

Figure 24. Effect of Heading Angle on HU-25C Maximum Empennage Root Bending Moment. 
The HU-25C was trimmed at the specified heading angle, six degrees toward inboard, at an initial location approximately $100 \mathrm{ft}$. outboard of the DC-8 trailing vortex ( $\mathrm{Y}=-160 \mathrm{ft}$.), and at vertical positions between 5-ft. above the vortex to 5-ft. below the vortex. The stick-fixed trajectory simulations were run as before, and the lateral trajectory simulations are shown below.

Falcon position is relative to the $\mathrm{DC}-8$

Crossing DC-8 wake at a $6^{\circ}$ relative flight path

Flights speeds of DC-8 and Falcon equal

Relative velocity of Falcon w.r.t. DC-8

Lateral: $v=V \sin (6)=56.7 \mathrm{ft} / \mathrm{s}$

Longitudunal: $u=V^{\prime}(1-\cos (6))=2.97 \mathrm{ft} / \mathrm{s}$

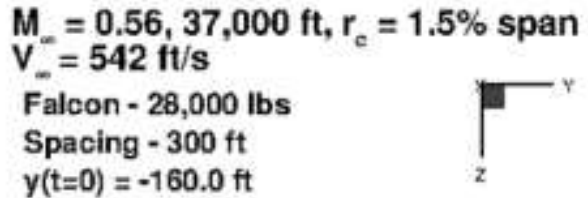

$y(t=0)=-160.0 \mathrm{ft}$

$z(t=0)=-5.0 \mathrm{ft}$, height relative to vortex

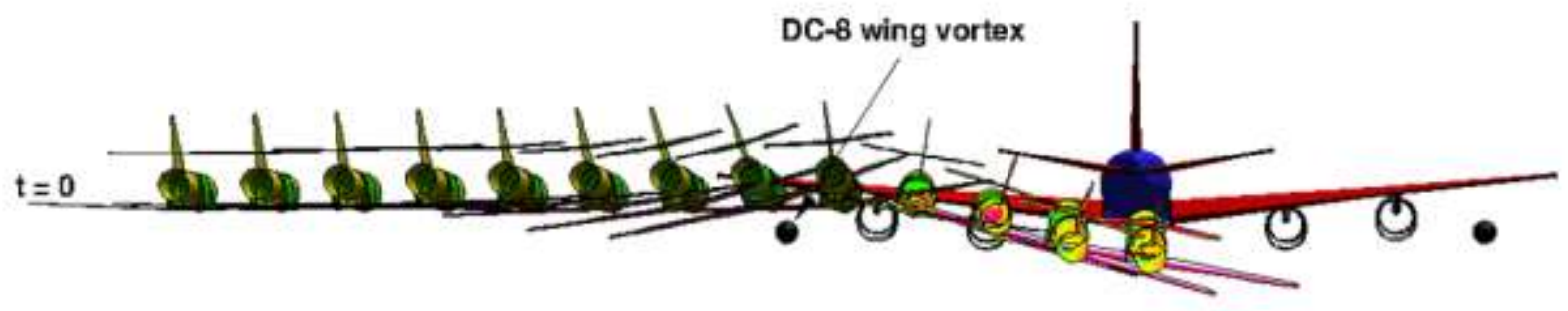

Falcon depicted every $0.25 \mathrm{sec}$

$t=3$

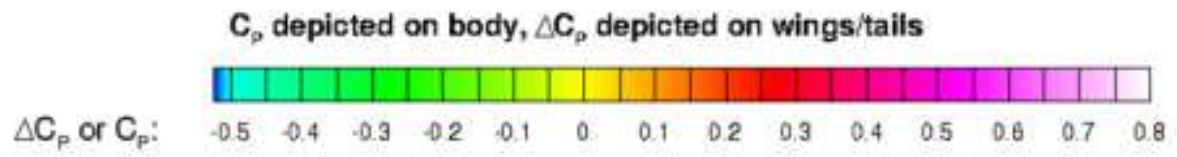

Figure 25. HU-25C Lateral Traverse, 6-Degree Heading, 5-ft. Above the Vortex.

Falcon position is relative to the $\mathrm{DC}-8$

Crossing DC-8 wake at a 6 relative flight path

Flights speeds of DC-8 and Falcon equal

Relative velocity of Falcon w.r.t. DC-8

Lateral: $v=V \sin (6)=56.7 \mathrm{ft} / \mathrm{s}$

Longitudunal: $u=V_{-}(1-\cos (6))=2.97 \mathrm{ft} / \mathrm{s}$

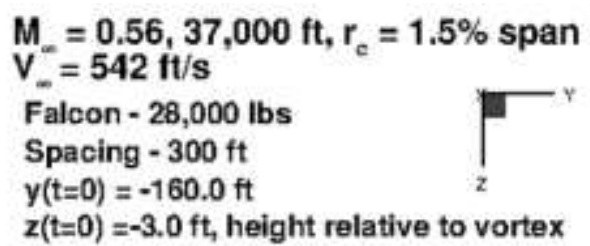

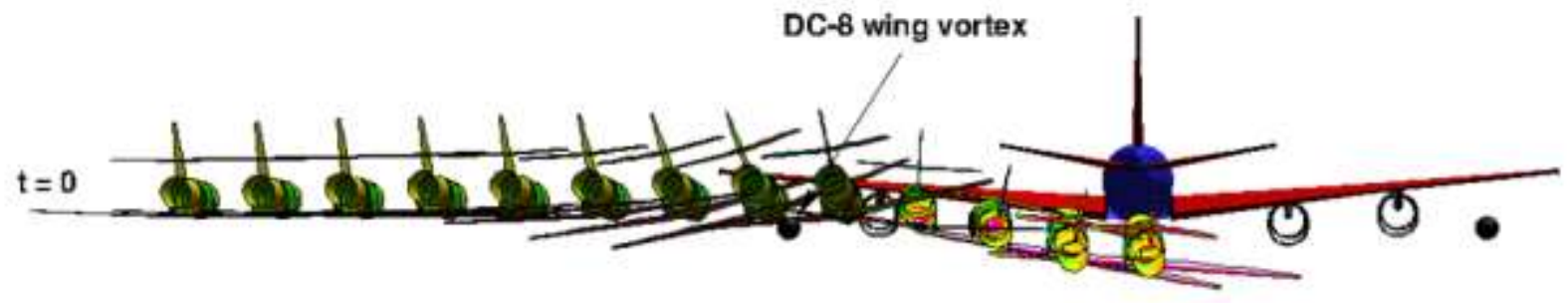

Falcon depicted every $0.25 \mathrm{sec}$

$t=3$

$\mathrm{C}_{\rho}$ depicted on body, $\triangle \mathrm{C}_{\rho}$ depicted on wings/tails

\begin{tabular}{|c|c|c|c|c|c|c|c|c|c|c|c|c|c|c|}
\hline & ] & & & & & & - & $\square$ & & 1 & 1 & 1 & \begin{tabular}{|l|l} 
& \\
\end{tabular} & \\
\hline$\Delta \mathrm{C}_{\mathrm{p}}$ or $\mathrm{C}_{\mathrm{p}}:$ & -0.5 & 0.4 & -0.3 & 0.2 & 0.1 & 0 & 0.1 & 0.2 & 0.3 & 0.4 & 0.5 & 0.0 & 0.7 & 0.8 \\
\hline
\end{tabular}

Figure 26. HU-25C Lateral Traverse, 6-Degree Heading, 3-ft. Above the Vortex.

16

American Institute of Aeronautics and Astronautics 
Falcon position is relative to the $\mathrm{DC}-8$

Crossing DC -8 wake at a $6^{\circ}$ relative flight path

Flights speeds of DC-8 and Falcon equal

Relative velocity of Falcon w.r.t. DC-8

Lateral: $v=V \sin (6)=56.7 \mathrm{ft}$ 's

Longitudunal: $u=V_{-}(1-\cos (6))=2.97 \mathrm{ft} / \mathrm{s}$
$M_{\infty}=0.56,37,000 \mathrm{ft}, \mathbf{r}_{\mathrm{c}}=1.5 \%$ span

$V_{\infty}^{\infty}=542 \mathrm{ft} / \mathrm{s}$

Falcon - 28,000 lbs

Spacing $-300 \mathrm{ft}$

$y(t=0)=-160.0 \mathrm{ft}$

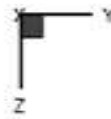

$z(t=0)=0.0 \mathrm{ft}$, height relative to vortex
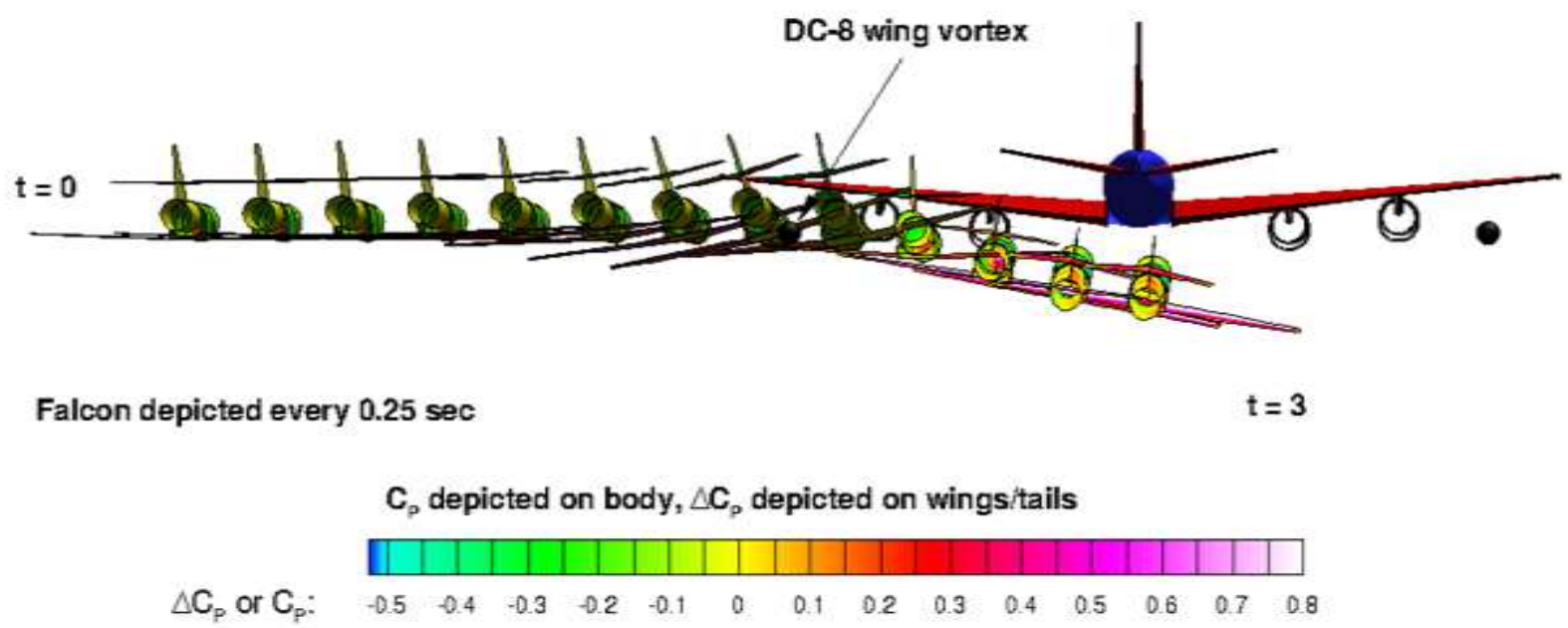

Figure 27. HU-25C Lateral Traverse, 6-Degree Heading, 0-ft. Above the Vortex.

Falcon position is relative to the $\mathrm{DC}-8$

Crossing DC-8 wake at a $6^{\circ}$ relative flight path

Flights speeds of DC-8 and Falcon equal

Relative velocity of Falcon w.r.t. DC-8

Lateral: $v=V \sin (6)=56.7 \mathrm{ft} / \mathrm{s}$

Longitudunal: $u=V_{-}(1-\cos (6))=2.97 \mathrm{ft} / \mathrm{s}$

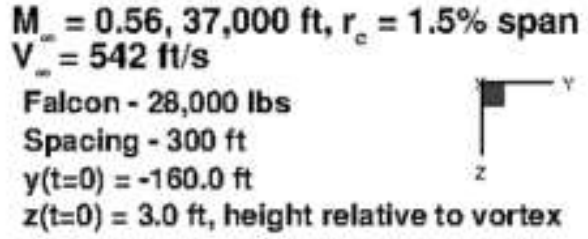

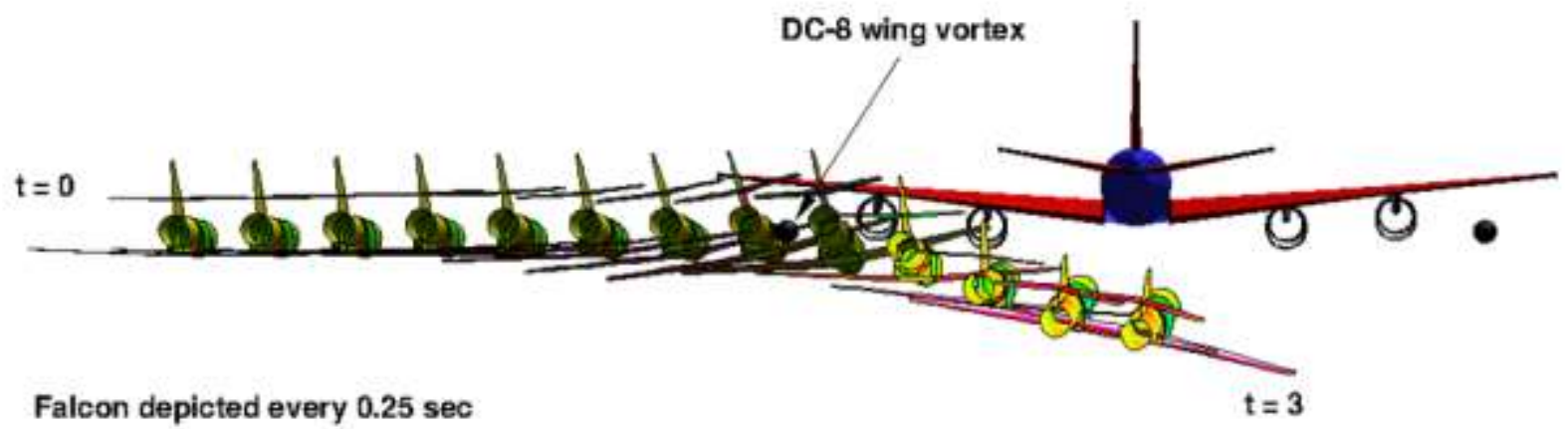

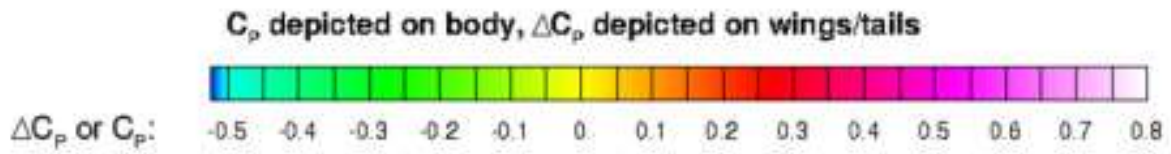

Figure 28. HU-25C Lateral Traverse, 6-Degree Heading, 3-ft. Below the Vortex. 
Falcon position is relative to the $\mathrm{DC}-8$

Crossing DC-8 wake at a $6^{\circ}$ relative flight path

Flights speeds of DC- 8 and Falcon equal

Relative velocity of Falcon w.r.t. DC-8

Lateral: $v=V \sin (6)=56.7 \mathrm{ft} / \mathrm{s}$

Longitudunal: $u=V_{-}(1-\cos (6))=2.97 \mathrm{ft} / \mathrm{s}$
$M_{c}=0.56,37,000 \mathrm{ft}, r_{c}=1.5 \%$ span

$\mathrm{V}_{-}=542 \mathrm{ft} / \mathrm{s}$

Falcon - $28,000 \mathrm{lbs}$

Spacing $-300 \mathrm{ft}$

$y(t=0)=-160.0 \mathrm{ft}$

$z(t=0)=5.0 \mathrm{ft}$, height relative to vortex
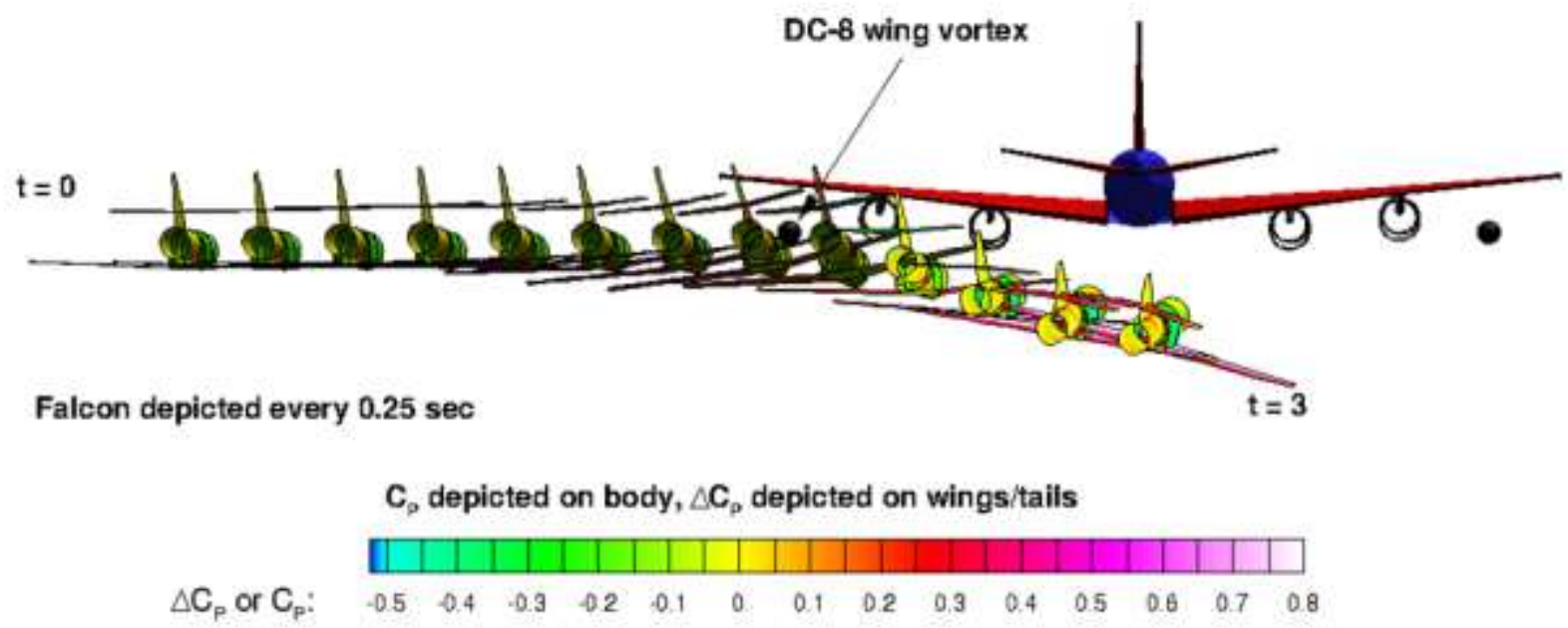

Figure 29. HU-25C Lateral Traverse, 6-Degree Heading, 5-ft. Below the Vortex.

Animations of these trajectory simulations were used for a visual assessment of the dynamic effects and a better understanding of the HU-25C flight characteristics under the influence of the DC-8 wake.

\section{Dynamic Loads}

For each of the trajectory simulations, the time history of the aircraft flight conditions and attitude, the overall aerodynamic forces and moments, and the aircraft component loads and bending moments are available.

The motion characteristics of the HU-25C during a vertical traverse starting directly above the DC- 8 primary vortex is shown in Fig. 30. This is the trajectory illustrated in Fig. 19. The vortex induced load on a tail component depends on the relative position of the primary vortex with respect to the HU-25C, and the maximum load on each component can occur at a different time in the trajectory. An illustration of the impact of small trajectory changes on the maximum root bending moment on the empennage is shown in Fig. 31. Notice that the dramatic reduction in bending moment at $\mathrm{Y}(0)<84 \mathrm{ft}$. is caused by the HU-25C rolling outboard away from the primary vortex. 

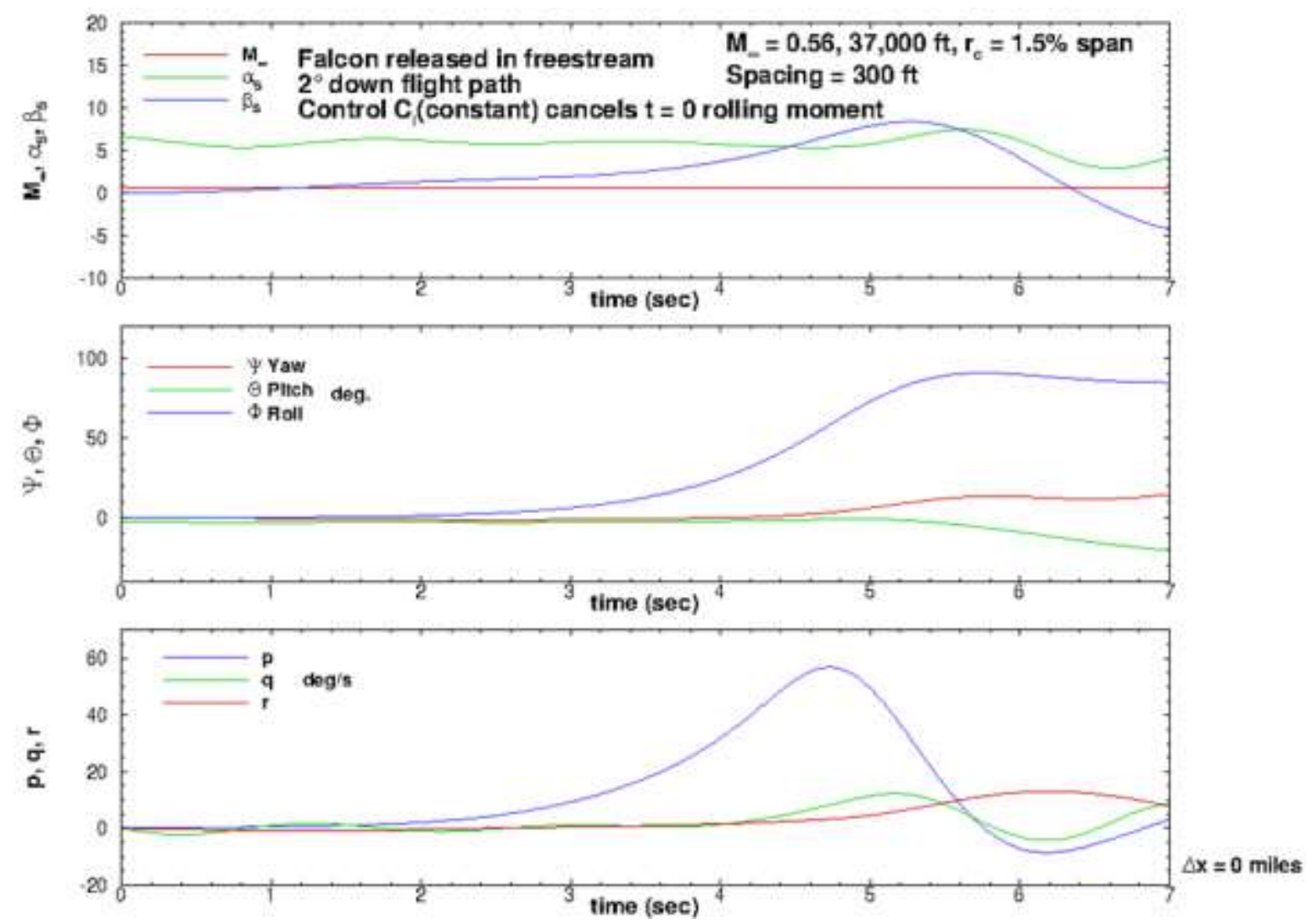

Figure 30. HU-25C Vertical Traverse, 2-Degree Descent, $Y(0)=-60 \mathrm{ft}$., $\mathrm{Z}(0)=100 \mathrm{ft}$.

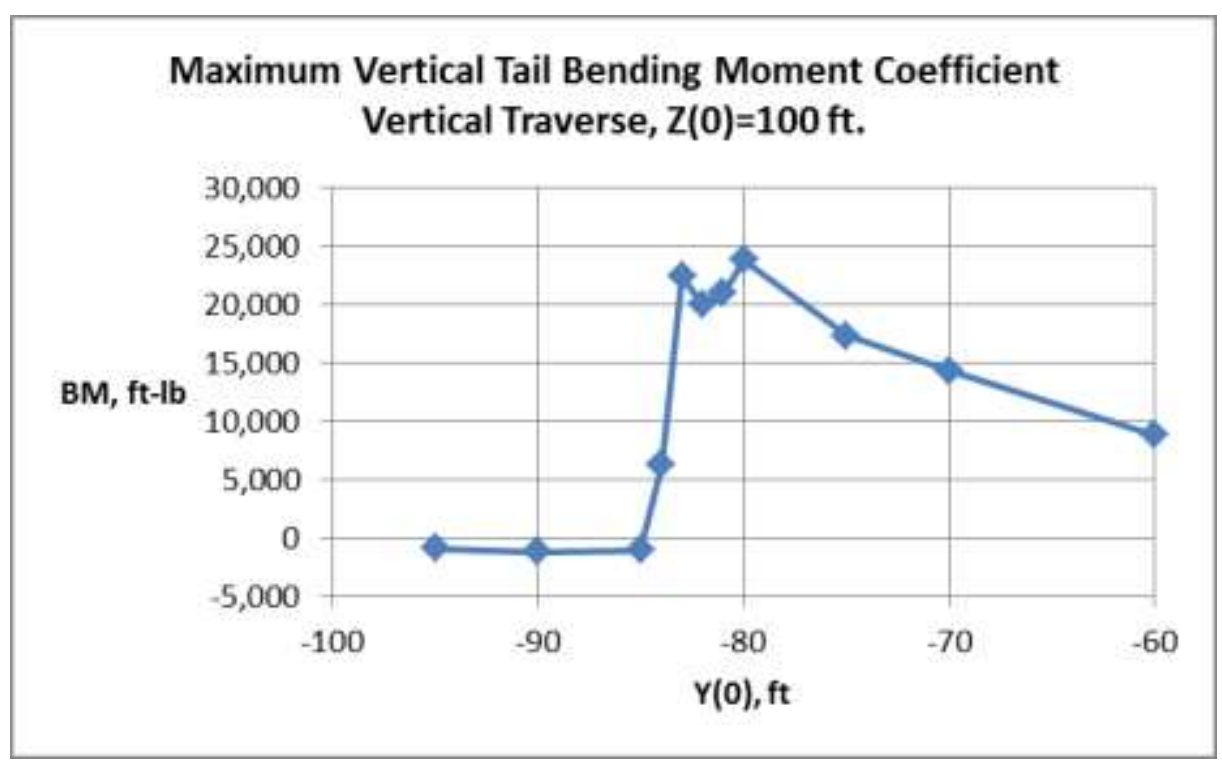

Figure 31. HU-25C Maximum Empennage Root Bending Moment, 2-Degree Vertical Traverse, 0 nm Trail Distance. 
The HU-25C motion characteristics during a horizontal traverse through the DC-8 primary vortex is shown in Fig. 32 for an initial starting point at the same vertical level as the vortex. The simulation corresponding to this result is similar to that shown in Fig. 27. The bottom segment of Fig. 32 shows the time history of the root bending moments of the tail components.
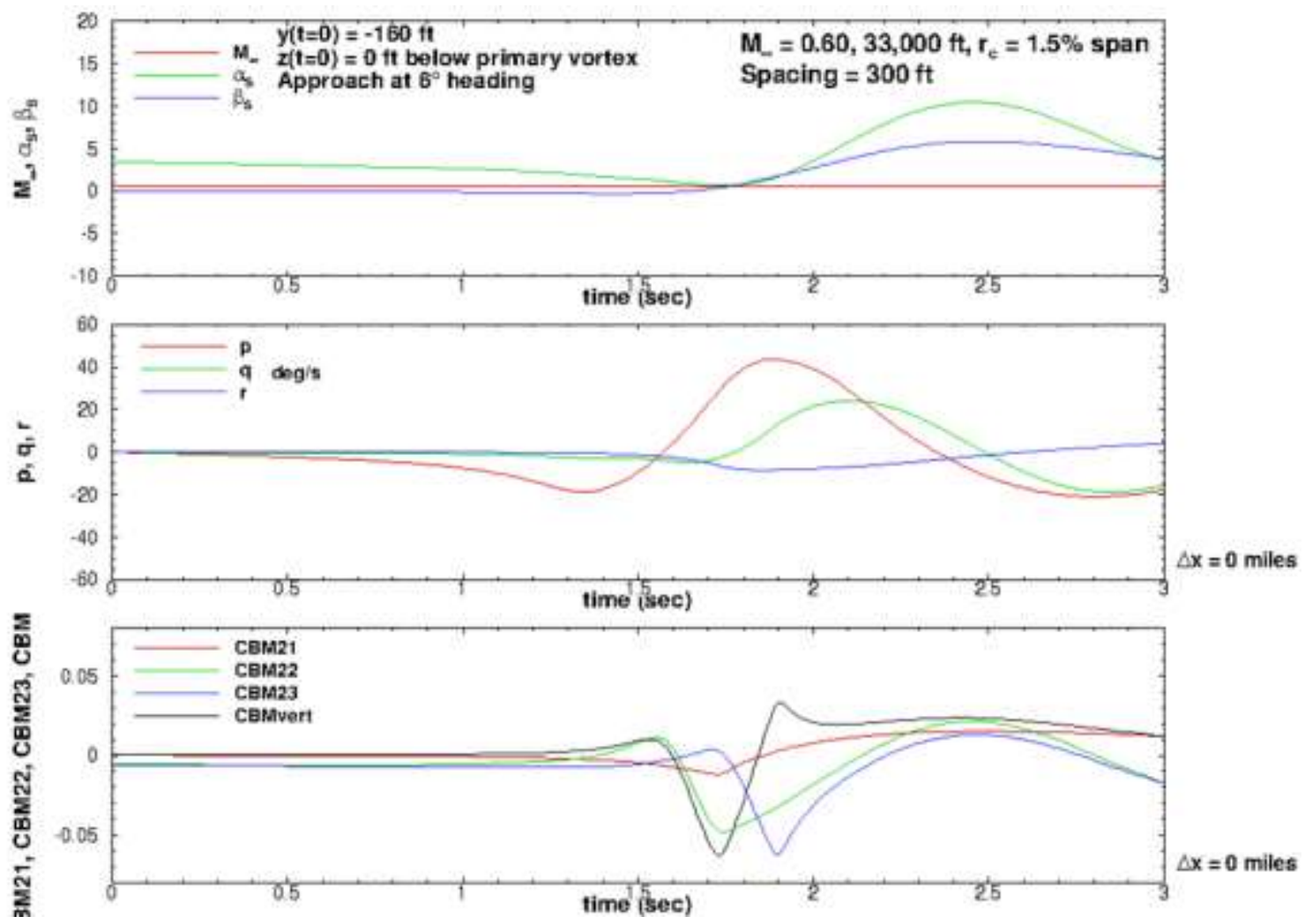

Figure 32. HU-25C Lateral Traverse, 6-Degree Heading, $Z(0)=0 \mathrm{ft}$.

The time histories of the component loads from the lateral trajectories produced the maximum empennage root bending moments as shown in Fig. 33. Note in this figure that maximum (positive) and minimum (negative) values for the bending moment are shown for each initial vertical starting position. The empennage is loaded in both directions during a trajectory, but in these cases, the negative moment is always the largest magnitude. 


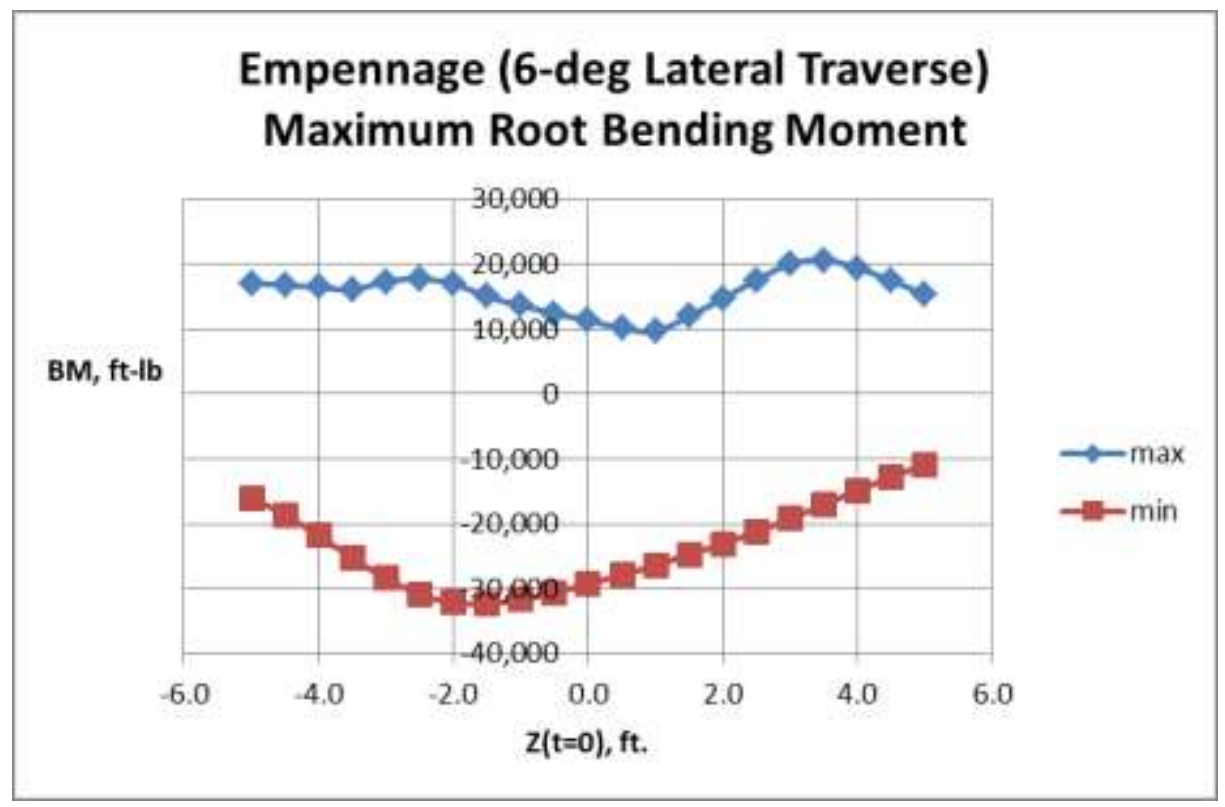

Figure 33. Effect of HU-25C Initial Vertical Position on Maximum Empennage Root Bending Moment in a 6-Degree Lateral Traverse at 0 nm Trail Distance.

\section{Safe Trail Distance}

The project's objective was to define by analysis a safe trail distance for the flight test. As discussed previously, the safe trail distance is that distance aft of the DC- 8 at which the maximum bending moment on the HU-25C tail does not exceed $70 \%$ of the design limit load. The critical tail load condition location was at first assumed to be at the empennage root, but this was later revised based on manufacturer information to be at the horizontal tail junction with the vertical tail.

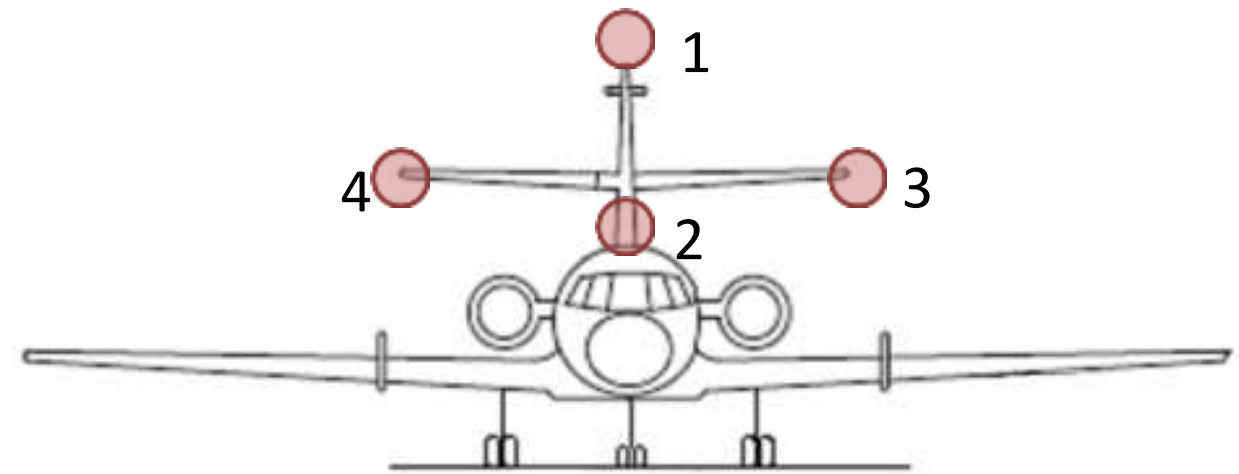

Figure 34. Trailing Vortex Positions for Trail Distance Validation.

For the validation of the ACCESS project safe trail distances, the NEAR model was run with the DC- 8 trailing vortex fixed at four specific locations with respect to the HU-25C tail section as shown in Fig. 34. Position 1 is at the tip of the vertical tail, position 2 is near the root of the vertical tail, and position 3 is at the tip of the left horizontal tail. Position 4 at the tip of the right horizontal tail produces nearly identical results as position 3 and will not be shown.

For the results to follow, the DC-8 weights are 170,000 and 230,000 lbs, and the flight conditions are Mach 0.6 at 33,000 ft. The maximum empennage root bending moments for the primary DC-8 vortex in positions 1 through 3 are shown in Figs. 35-37, respectively. Note that 70\% DLL is shown as the green dashed line. The maximum horizontal tail junction bending moments for the three vortex locations are shown in Figs. 38-40. 


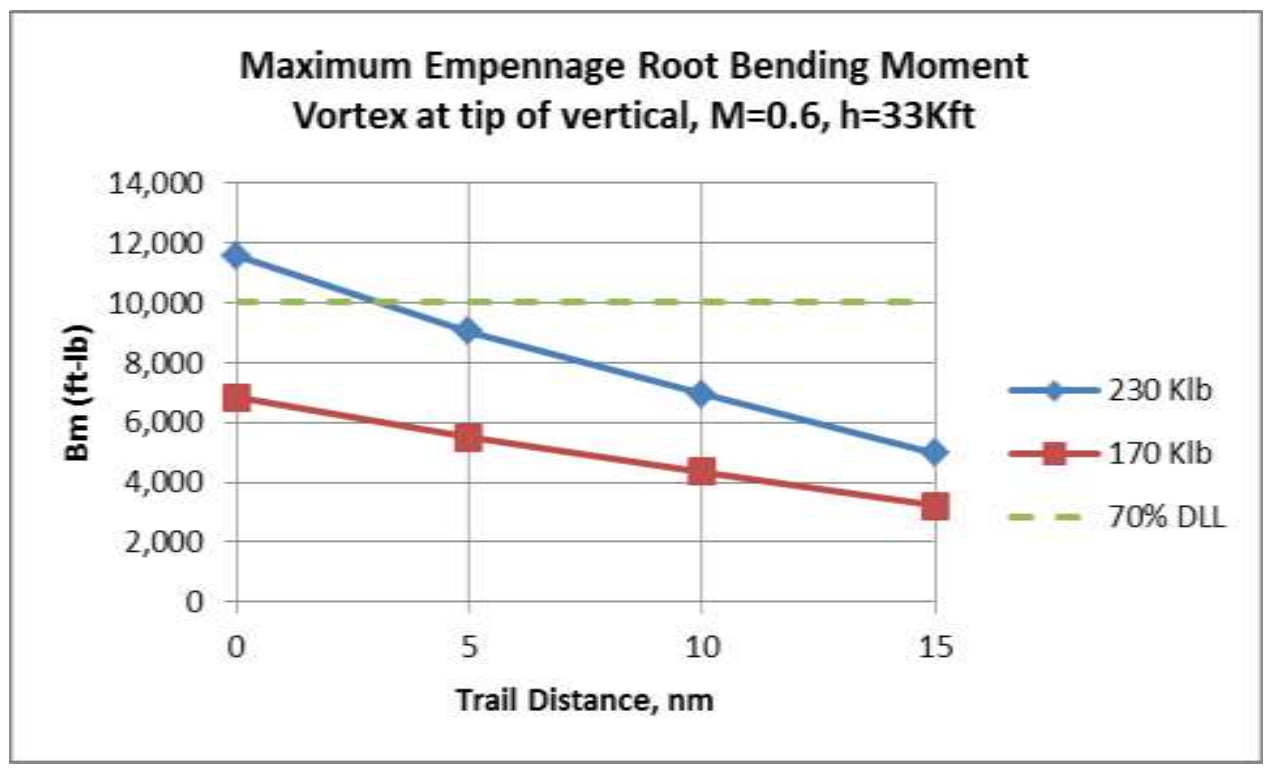

Figure 35. Maximum HU-25C Empennage Root Bending Moment, Vortex Position 1.

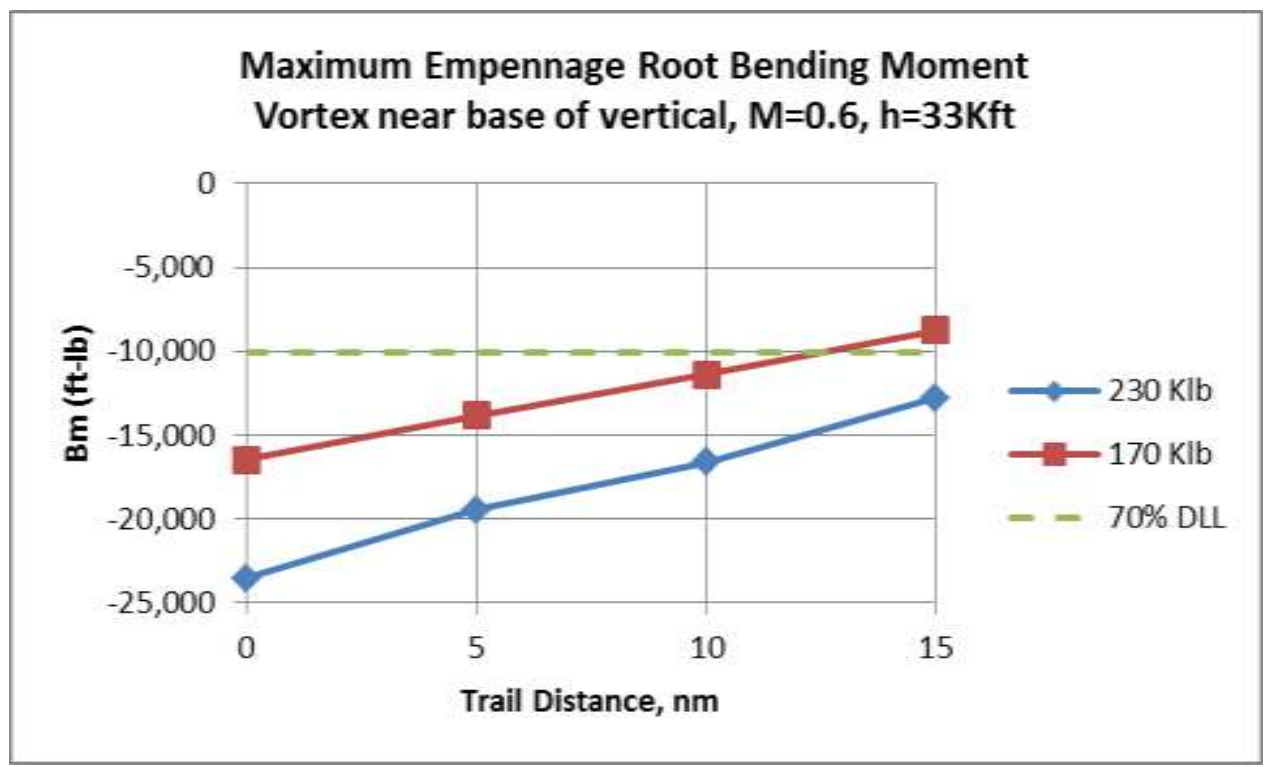

Figure 36. Maximum HU-25C Empennage Root Bending Moment, Vortex Position 2. 


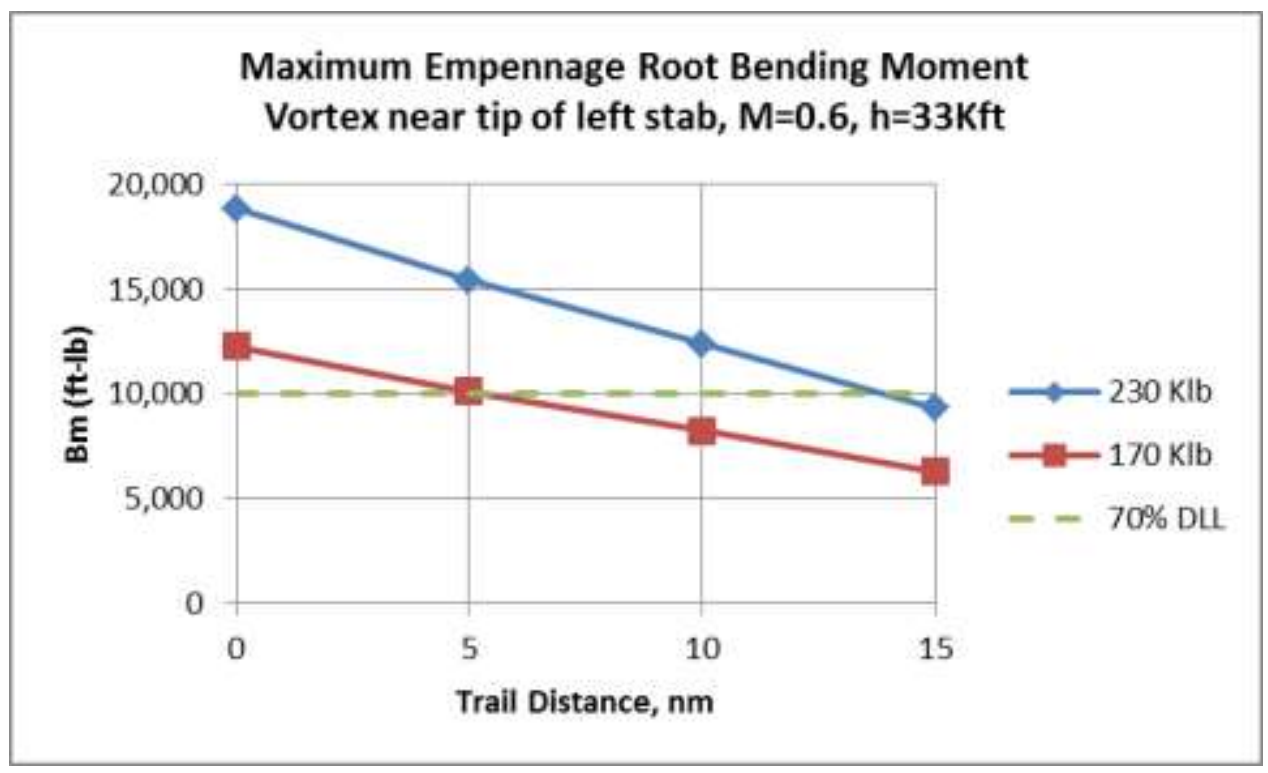

Figure 37. Maximum HU-25C Empennage Root Bending Moment, Vortex Position 3.

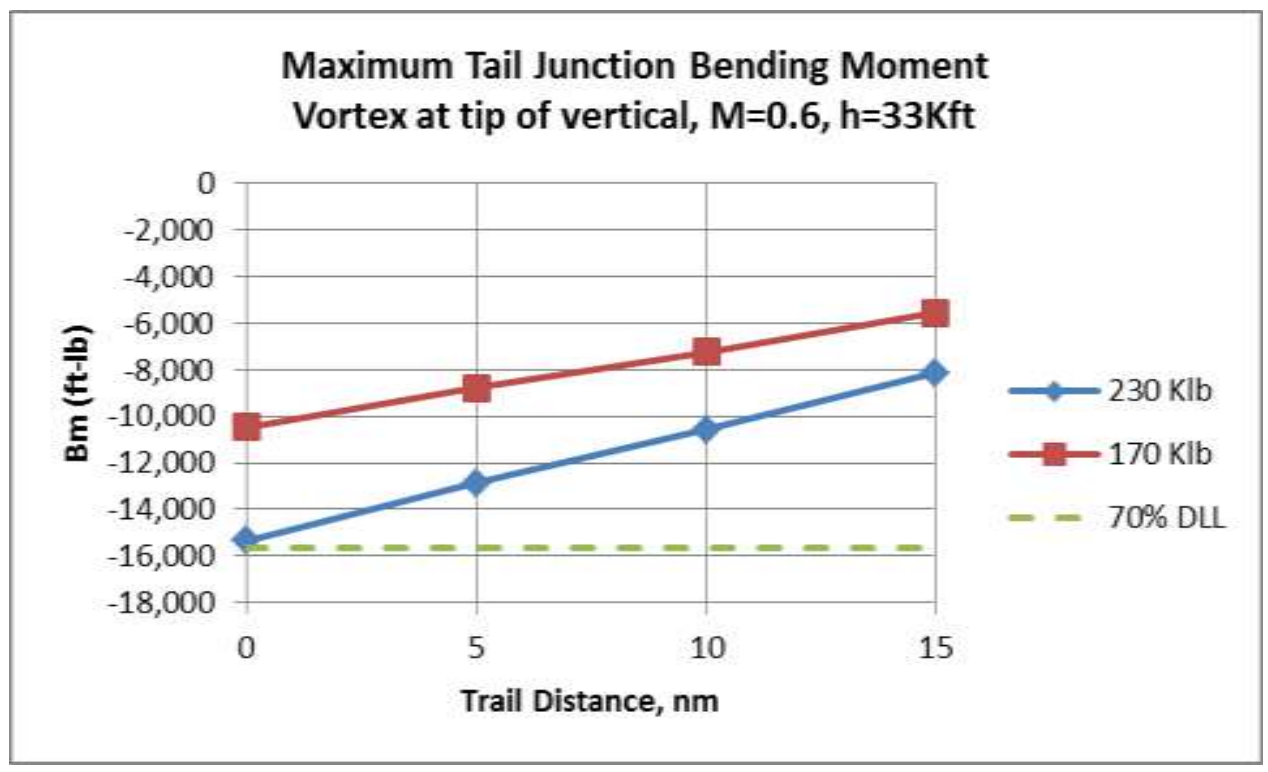

Figure 38. Maximum HU-25C Tail Junction Bending Moment, Vortex Position 1. 


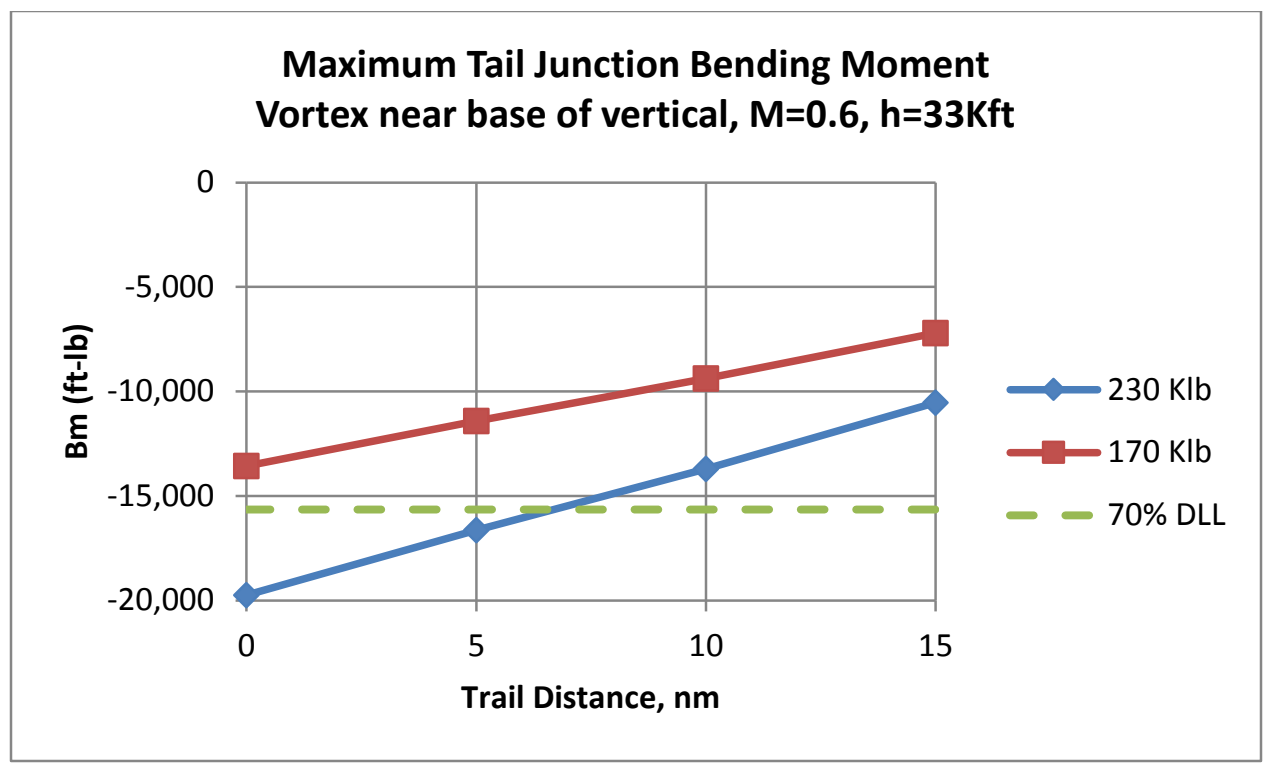

Figure 39. Maximum HU-25C Tail Junction Bending Moment, Vortex Position 2.

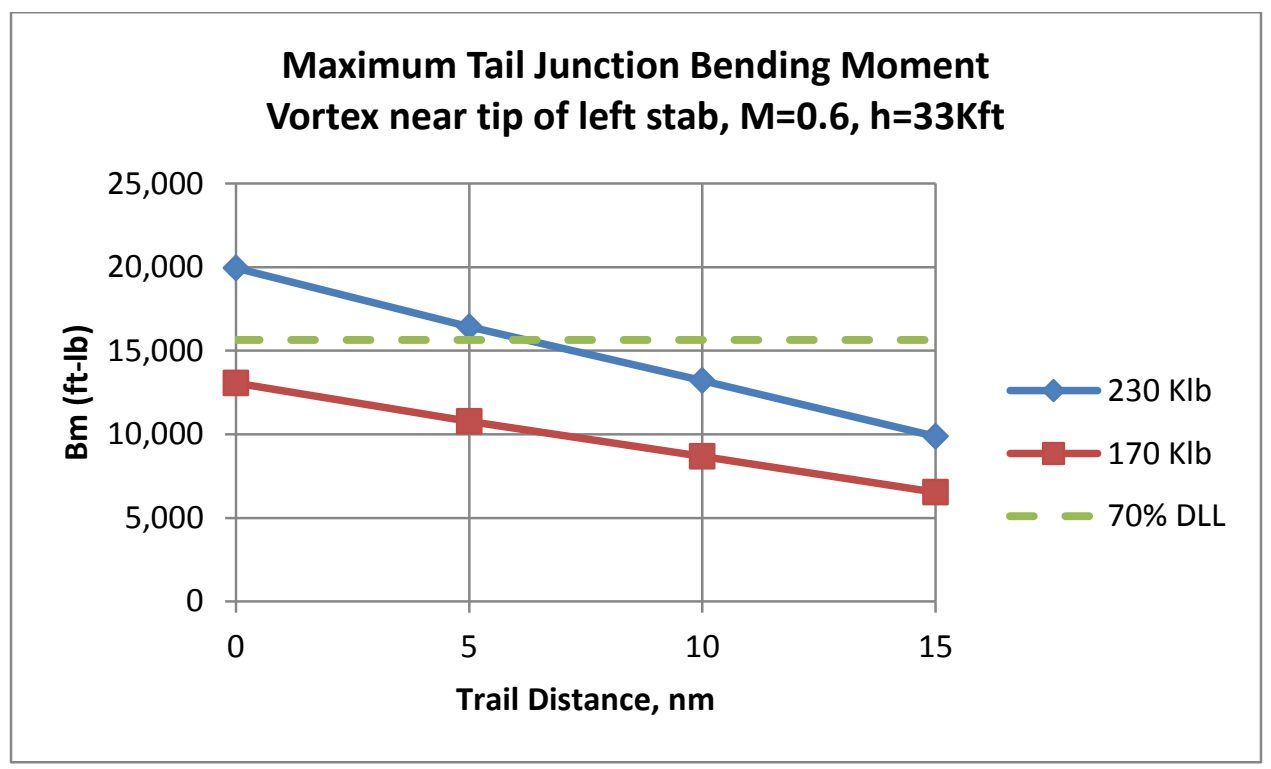

Figure 40. Maximum HU-25C Tail Junction Bending Moment, Vortex Position 3.

These results verified the ACCESS project team estimate of $15 \mathrm{~nm}$ as a safe trail distance; however, they were also less conservative than the project estimates and showed much closer safe trail distances for certain trailing vortex positions with respect to the $\mathrm{HU}-25 \mathrm{C}$ tail. 


\section{Conclusions and Discussion}

The independent static loads analyses described in this paper corroborated the project-determined safe test flight trail distances, and the test flights were conducted safely and with test results generally consistent with predictions during the close encounters with the DC-8 trailing vortices.

The flight characteristics experienced by the HU-25C trailing aircraft during vortex traverses were consistent with the dynamic simulation predictions according to pilot comments. The simulation results shown above, that a lateral traverse through the DC- 8 vortex is more benign in pitch, roll, yaw, than a vertical traverse, dictated a change in the test flight procedures.

The results of this independent analysis demonstrate that reduced-order prediction methods are extremely useful for complex aerodynamic problems, particularly when it is necessary to analyze or reanalyze tens of thousands of flow conditions and relative position of multiple aircraft including dynamic 6-DOF simulations.

\section{References}

${ }^{1}$ ACCESS Web Site: http://www.nasa.gov/aero/access-II.html\#.VPCdfOGsnVo

${ }^{2}$ Kelly, M. J., et al, "Probing Aircraft Flight Test Hazard Mitigation for the Alternative Fuel Effects on Contrails \& Cruise Emissions (ACCESS) Research Team,” NESC-RP-12-00822 Vol. 1 and 2, April 18, 2013.

${ }^{3}$ Gerz, T., Holzapfel, F. and Darracq, D., "Commercial Aircraft Wake Vortices," Progress in Aerospace Sciences, Vol. 38, p.181-208, 2002.

${ }^{4}$ Proctor, F. H., Ahmad, N. N., Switzer, G. S., Limon Duparcmeur, F. M., “Three-Phased Wake Vortex Decay,” AIAA 2010-7991, August 2010.

${ }^{5}$ Ahmad, N. N., Proctor, F. H., Duparcmeur, F. M. L., and Jacob, D., "Review of Idealized Aircraft Wake Vortex Models," AIAA 2014-0927, January 2014.

${ }^{6}$ Lesieutre, D. J. and Perkins, S. C., Jr., "Store Separation Prediction Program STRLNCH, Version March 2013”, NEAR TR 655, Nielsen Engineering \& Research, Inc., Mountain View, CA, March 2013.

${ }^{7}$ Dillenius, M. F. E., Love, J. F., Hegedus, M. C., and Lesieutre, D. J., "Program STRLNCH for Simulating Missile Launch from a Maneuvering Parent Aircraft at Subsonic Speed," NEAR TR 509, Nielsen Engineering \& Research, Mountain View, CA, 1996.

${ }^{8}$ Dillenius, M. F. E., Goodwin, F. K., and Nielsen, J. N., "Analytical Prediction of Store Separation Characteristics from Subsonic Aircraft," Journal of Aircraft, Vol. 12, No. 10, October 1975, pp. 812-818.

${ }^{9}$ Dillenius, M. F. E., Goodwin, F. K., and Nielsen, J. N., "Extension of the Method for Predicting Six-Degree-of-Freedom Store Separation Trajectories at Speeds up to the Critical Speed to Include a Fuselage with Noncircular Cross Section, Volume I - Theoretical Methods and Comparisons with Experiment," AFFDL-TR-74-130, AF Flight Dynamics Lab., Wright-Patterson AFB, OH, March 1974.

${ }^{10}$ Lesieutre, D. J., "Detailed Aerodynamic Prediction Program MISDL, Code User's Manual, Version October 2013," NEAR TR 651, Nielsen Engineering \& Research, Inc., Mountain View, CA, October 2013.

${ }^{11}$ Lesieutre, D. J. and Quijano, O. E., "Studies of Vortex Interference Associated with Missile Configurations," AIAA2014-0213, January 2014.

${ }^{12}$ McDaniel, M. A., Evans, C. and Lesieutre, D. J., "The Effect of Tail Fin Parameters on the Induced Roll of a CanardControlled Missile," AIAA 2010-4226, June 2010.

${ }^{13}$ Lesieutre, D. J., Dillenius, M. F. E., and Lesieutre, T. O., "Multidisciplinary Design Optimization of Missile Configurations and Fin Planforms for Improved Performance," 7th Symposium on Multidisciplinary Analysis and Optimization, St. Louis, MO, AIAA-1998-4890, September 1998.

${ }^{14}$ Lesieutre, D. J., Dillenius, M. F. E., Love, J. F., and Perkins, S. C., Jr., "Nonlinear Engineering-Level Missile Aerodynamics Prediction Methods MISL3, MISDL, and NEARZEUSIN/ZEUSBL," CEAS Aerospace Aerodynamics Research Conference, London, UK, June 10-12, 2003.

${ }^{15}$ Lesieutre, D. J., Love, J. F., and Dillenius, M. F. E., "Prediction of the Nonlinear Aerodynamic Characteristics of Tandem-Control and Rolling-Tail Missiles," AIAA 2002-4511, August 2002.

${ }^{16}$ Dillenius, M. F. E., Lesieutre, D. J., Hegedus, M. C., Perkins, S. C., Jr., Love, J. F., and Lesieutre, T. O., "EngineeringIntermediate-, and High-Level Aerodynamic Prediction Methods and Applications," Journal of Spacecraft and Rockets, Vol. 36, No. 5, Sep.-Oct. 1999, pp. 609-620.

${ }^{17}$ Hallberg, E., Cenko, A., and Dillenius, M. F. E., "Store Separation Trajectory Simulation for the High Speed AntiRadiation Demonstrator (HSAD) from the F-4 Aircraft," AIAA 2008-6381, 2008.

${ }^{18}$ Lesieutre, D. J., Dillenius, M. F. E., and Gjestvang, J. A., "Store Separation Simulation of the Penguin Missile from Helicopters," Paper Number 9, Presented at NATO-RTO Symposium on Innovative Missile Systems, Amsterdam, The Netherlands, May 2006, RTO-MP-AVT-135.

${ }^{19}$ Dillenius, M. F. E., Lesieutre, D. J., Perkins, S. C., Jr., and Love, J. F., "Prediction of Nonlinear Missile Aerodynamics with Applications Including Store Separation,” RTO-MP-5, Missile Aerodynamics, November 1998. 
${ }^{20}$ Dillenius, M. F. E., Perkins, S. C., Jr., and Lesieutre, D. J., "Engineering Level Methods for Carriage Loads, HighAlpha Launch from Pitching Aircraft, and Submunition Aerodynamics," AGARD CP-570, Aerodynamics of Store Integration and Separation, February 1996, pp. 10-1-10-9.

${ }^{21}$ Mendenhall, M. R., Lesieutre, T. O., Lesieutre, D. J., and Dillenius, M. F. E., "Carriage and Release Aerodynamics of the Pegasus Air-Launched Space Booster," AGARD CP-570, Aerodynamics of Store Integration and Separation, February 1996, pp. 11-1-11-12.

${ }^{22}$ Dillenius, M. F. E., Perkins, S. C., Jr., Johnson, D. L., and Lesieutre, D. J., "Engineering Level Predictions for External Store Separation and Submunition Aerodynamics," Store Carriage, Integration, and Release Proceedings, Royal Aeronautical Society, April 1990, pp. 18.1-18.21.

${ }^{23}$ Dillenius, M. F. E., Lesieutre, D. J., Perkins, S. C., Jr., Jeter, E. L., and Schulz, J. C., "Methodology for Aerostructural Analysis of a Missile Attached to a Maneuvering Aircraft," AIAA 89-0480, January 1989.

${ }^{24}$ Perkins, S. C., Jr., Mendenhall, M. R., and Dillenius, M. F. E., "Analytical Investigation of Two Subsonic Store/ Aircraft Configurations,” NEAR TR 378, Nielsen Engineering \& Research, Mountain View, CA, April 1987.

${ }^{25}$ Lesieutre, D. J. and Dillenius, M. F. E., “AV-8B Aircraft Mathematical Model for NEAR Subsonic Six-Degree-ofFreedom (6-DOF) Store Separation Code," NEAR TR 368, Nielsen Engineering \& Research, Mountain View, CA, October 1986. 